El imperativo de transparencia patrimonial del deudor como requisito funcional para una ejecución civil eficiente The transparency of debtors` assets as a functional requirement for an efficient civil enforcement

Álvaro Pérez Ragone - Oscar Silva Álvarez

páginas 79 - 115

\title{
EL IMPERATIVO DE TRANSPARENCIA PATRIMONIAL DEL DEUDOR COMO REQUISITO FUNCIONAL PARA UNA EJECUCIÓN CIVIL EFICIENTE*
}

\author{
THE TRANSPARENCY OF DEBTORS' ASSETS AS A \\ FUNCTIONAL REQUIREMENT FOR AN EFFICIENT CIVIL \\ ENFORCEMENT
}

\author{
Álvaro Pérez Ragone**. Oscar Silva Álvarez***
}

\begin{abstract}
RESUMEN
En el presente artículo, y luego de entregar algunos planteamientos generales sobre la ejecución como momento relevante de la jurisdicción, los autores abordan uno de los tópicos principales en la eficacia del sistema ejecutivo como instrumento satisfactor de los derechos del acreedor ya declarados, pero no realizados: la transparencia en el patrimonio del deudor.
\end{abstract}

$\mathrm{Al}$ respecto, delinean algunos de sus componentes más importantes, para concluir con una visión general acerca de lo que establece el PCPC, en relación con este tema.

\footnotetext{
* Trabajo recibido el 26 de septiembre y aprobado el 2 de noviembre de 2009. Este artículo forma parte de Proyecto Fondecyt de iniciación "Estudio histórico, comparado y dogmático de las conductas no cooperativas de las partes en el proceso civil" ( $\left.{ }^{\circ} 11070054\right)$.

** Abogado (Universidad Nacional de Tucumán, Argentina), LL.M. y Doctor en Derecho (Universidad de Colonia, Alemania), Profesor de Derecho Procesal Civil de la Pontificia Universidad Católica de Valparaíso. Correo electrónico: alvaro.perez@ucv.cl

*** Abogado (Pontificia Universidad Católica de Valparaíso), Doctor (c) en Derecho (Pontificia Universidad Católica de Valparaíso), Profesor contratado de Derecho Procesal Civil de la Pontificia Universidad Católica de Valparaíso y de la Universidad de Viña del Mar. Los autores agradecen los comentarios, correcciones, críticas y aportes realizados para este trabajo a Dr. Christoph Kern, Prof. Dr. Luis Guilherme Marinoni, Prof. Dr. Sergio Cruz Arenhart y al grupo de estudiantes ayudantes de investigación Gabriela Varas, Monserrat Madariaga y Artemio Aguilar.
} 


\begin{abstract}
In the present article, and alter deliver some general approaches about the judgements enforcement and debts collection, the authors presents with a critical approach one of the main topics on the efficacy of the enforcement system, as a satisfactory instrument of the creditor's rights already declared, but not achieved: the transparency of the debtor's assets.
\end{abstract}

In this regard, they outline some of its most important components, to conclude with a general overview of what is regarded in the PCPC, about this issue.

\title{
PALABRAS CLAVES
}

Transparencia patrimonial, investigación de bienes, manifestación de bienes, medidas coercitivas, deber de información.

\section{KEY-WORDS}

Transparency of assets, investigation of assets, assets disclosure, coercive measures, duty of information.

\section{1- Introducción.}

Hasta una época relativamente reciente, uno de los aspectos más abandonados por la doctrina procesal fue, precisamente, el último de los momentos jurisdiccionales, y que corresponde a la ejecución. Lo anterior resulta una constatación que sorprende, considerando la razón de ser del derecho procesal, y que no es otra que concretar, en la medida de lo posible, el concepto de justicia, satisfaciendo el interés necesitado de tutela.

En efecto, la jurisdicción pensada sin posibilidad que lo decidido se cumpla actual o potencialmente, implica la negación del funcionamiento del Estado de Derecho. Obtener un pronunciamiento con las condiciones antes mencionadas ya no es suficiente, cuando la sola voluntad de la parte vencida (ahora deudor) se transforma en un obstáculo para el vencedor (ahora acreedor). Absurdo sería pensar en las bondades de una solución justa y oportuna, si no puede cumplirse lo señalado por ésta ${ }^{1}$. El Tribunal Europeo de Derechos Humanos ha reconocido que el derecho de acceso a la justicia fundado en el artículo $6 \mathrm{CEDH}$ se justifica siempre que se logre asistir al acreedor para una satisfacción efectiva de su derecho ${ }^{2}$.

1 Guinchard, Serge, "La garantie de l'éxecution de la decisión du Juge” en Droit Processuel, Delloz, París, 2009, pp. 1015 y ss.; Pellegrini, Ada, "Cumprimento da sentença”, VV.AA. Temas atuais da Execução civil, Sao Paulo, Ed. Revista dos Tribunais, San Pablo, 2007, pp. 1-10; Menut, Mesut, "Pour un Code mondial de l'exécution" en L'harmonization des procédures d'exécution dans un espace de justice sans frontière, Ed. Juridique et T., Paris, 2006, pp. 21-75.

2 Del 12.12.2002 - 59021/00 "Kalogeropoulou y otros contra Grecia y Alemania", 2004, Neue Juristische Wochenschrift (NJW), p. 273. 
El imperativo de transparencia patrimonial del deudor como requisito funcional para una ejecución civil eficiente The transparency of debtors` assets as a functional requirement for an efficient civil enforcement

La concepción de la acción en su máximo grado de abstracción, implicó aislarse del derecho material, concluyendo finalmente en un derecho procesal "autónomo" del derecho sustantivo; autonomía que terminó manifestándose en incoherencia y disfuncionalidad de un "derecho procesal de laboratorio", enfrentado con un derecho sustantivo de la realidad. Es coherente con ello la poca preocupación por la eficiencia de la ejecución ${ }^{3}$.

En primer lugar, la obligatoriedad de las sentencias parece ser una premisa tabú y, a veces, utópica. Cuando de la tutela efectiva de un derecho se trata, aún debe recorrerse un camino donde variables temporales, e incluso de potencialidad satisfactiva de un crédito que se ejecuta (ya no se discute), quedan en manos y arbitrio del deudor. Pensar en la ejecución y el diseño de distintos sistemas sin contemplar la necesidad acceder y manejar la información necesaria sobre el ejecutado constituye una quimera. Dicha información ya no tiene mucho que ver con los clásicos requisitos de una "demanda" en un proceso de conocimiento, sino con detalles relativos la dirección (o ubicuidad física) correcta del deudor, una adecuada y completa información sobre sus activos, en lo posible con información provista por él mismo y/o su entorno cercano, para, finalmente, sumar la información de terceros pertinente sobre el ejecutado y sus bienes. La obtención y el cruce de esta información determinan el éxito o fracaso de la ejecución. Desde actuaciones procesales como las notificaciones, hasta la concreción de las medidas de agresión patrimonial, dependen de dicha información. Al respecto, debe siempre contemplarse la alta probabilidad de que el deudor no cooperará fácilmente para brindar, voluntariamente, la información requerida, que en muchos casos podrá ocultarla y hasta tergiversarla ${ }^{4}$. Esto se relaciona con un deber de transparencia patrimonial que asume el deudor incumplidor frente al acreedor, pero principalmente frente al Estado en el ejercicio de función jurisdiccional ejecutiva: cooperar en la ejecución positiva (brindando la información veraz necesaria para cubrir el crédito de la parte ejecutante) y negativamente (no omitiendo u obstaculizando el acceso a dicha información.

Sólo como ejemplo, una fuente confiable y objetiva para acceder a estos datos la ha constituido en la UE el conjunto de diferentes registros de información sobre las calidades

Prütting, Hanns, “Rezeption und Ausstrahlung des Zivilprozess- Globalisierung des Verfahrens?” en Lieber Amicorum Lindacher, Heymanns, Colonia, 2007, pp. 89-100; Carpi, Federico, "Riflessioni sui rapporti fra l'art. 111 della Costituzione ed il processo esecutivo", 2002, Rivista trimestrale di diritto e procedura civile, Milano, Giuffré, n. ${ }^{\circ}$ 2, pp. 390 y ss.

4 Ya tratando sobre la necesidad reforma y regulación especial sobre la transparencia patrimonial : Merlin Elena, "L'individuazione dei beni da pignorare e la <trasparenza> dei patrimoni: riflessioni de iure condendo" ,1993, en Giurisprudenza Italiana, IV, pp. 205-210; en Francia se instó la discusión doctrinaria el caso "Calvet" ver así Deboissy, Florence-Jean y Saint -Pau, Christophe, La divulgation d'une information patrimoniale, Dalloz, Paris, 2000, pp. 267-274; Wagner, Gerhard, "Urkundenedition durch Prozessparteien - Auskunftpflicht und Weigerungsrechte”, 2007, Juristen Zeitung, pp. 706-710. Comp. Igualmente con un tratamiendo de teoría general del proceso Leval, George de, Éléments de procédure civile. Larcier, Lovaina, 2005, pp. 5-18. 
Álvaro Pérez Ragone

Oscar Silva Álvarez

personales del deudor, su giro, sus bienes registrables o no, además de referencias a su residencia. Ahora bien, idealmente, los "registros" debieran contemplar mecanismos adecuados para el acceso y manejo de la información que contengan, de modo que, bajo premisas de necesidad, idoneidad y proporcionalidad, puedan los interesados acceder a los mismos y hacer uso de dicha información. Así, el hecho de tratarse de registros públicos o dependientes para su acceso del requerimiento de un órgano jurisdiccional, la cantidad y calidad (fiabilidad y actualización) de la información, y la aplicación de nuevas tecnologías dependen de un marco regulatorio adecuado, que impida cometer excesos y proteja información y datos personales.

Tomando un caso europeo, Alemania tiene bases de datos de administración regional o por estados federales, focalizadas en los bienes muebles o inmuebles con descripción del propietario. Contrariamente, Inglaterra maneja información de registros centralizados, con énfasis en las calidades de los bienes, independientes del o los propietarios ${ }^{5}$. Un rol fundamental lo desempeñan los registros de morosidad, sobreendeudamiento e insolvencia, existentes en países como España, Francia, Italia, Alemania, Austria Reino Unido, Dinamarca, Suecia. Y no menos importantes son los registros que permiten el cruce de información sobre el deudor, sobre la base de sus condiciones tributarias y de seguridad social ${ }^{6}$.

En segundo lugar, el acreedor suele enfrentarse con la compleja situación derivada de la ausencia de instrumentos procesales que permitan detectar el patrimonio de su deudor; situación que, mayormente, se traduce en la frustración de la satisfacción del crédito. El derecho de acción garantiza la tutela jurisdiccional efectiva, para lo que éste debe ser relacionado con las formas de protección jurisdiccional del derecho material. Estas formas de protección del derecho material pueden ser divididas en específica y por el equivalente pecuniario.

La protección o tutela específica del derecho material es aquella que está preocupada de la integridad del derecho, y no se limita (y resigna) simplemente al equivalente monetario, siendo conceptos contrapuestos en ese sentido. Puede decirse que la tutela jurisdiccional que protege el derecho sólo mediante la indemnización como equivalente o sucedáneo de la obligación incumplida o cumplida de modo imperfecto, es justamente una tutela que resigna un objetivo principal.

Cumplir por equivalente implica, en cierto grado, una conducta cooperativa por parte del

5 Para un estudio detallado sobre el tema ver Rink, Florian, Die Sicherheit von Grundpfandrechten in Deutschland und England. Mohr Siebeck, Tübingen, 2006, pp. 7-60.

$6 \quad$ Verbeke, Alain, "Quel huissier de justice pour l'Europe?" en Le droit processuel et le droit de l'exécution (Coord. Isnard, Jacques-Normand, Jacques), Dalloz, Paris, 2002, pp. 309-314; comp. Hesse, Michael , Gläubigerinformation in der Insolvenz . Ed. Mohr Siebeck, Tübingen, 2008, pp. 10-33. 
El imperativo de transparencia patrimonial del deudor como requisito funcional para una ejecución civil eficiente The transparency of debtors` assets as a functional requirement for an efficient civil enforcement

deudor, para poner a disposición su patrimonio para la ejecución ${ }^{7}$. Ahora ello no debiera significar un "peso" adicional al deudor, ya que era una consecuencia previsible en caso de incumplimiento. Sin embargo, la regulación procesal para satisacer por ejecución el crédito del ejecutante pone la carga en el ejecutado al momento de determinar sobre qué bienes se va a llevar adelante la ejecución. La cooperación impuesta en faz de ejecución parece no tener relevancia. En definitiva, se trata de un círculo vicioso, donde el peso recae siempre en quien, al menos con alto grado de credibilidad (título ejecutivo), le asiste la razón. Solo estas apreciaciones permiten al menos por ahora trabajar con la hipótesis del alejamiento (e inoperancia) del proceso en relación al derecho sustantivo.

La preocupación por una adecuada tutela ejecutiva del crédito tanto en las cobranzas o ejecuciones dinerarias como en otras, han recibido una atención preferente dentro del derecho procesal civil comunitario europeo ${ }^{8}$. Si el derecho a un juez, un buen juez y un proceso justo y

Comp. esta idea inicial a la sostenida por Ortells Ramos, Manuel, La ejecución de condenas no dinerarias en la Ley de Enjuiciamiento Civil, La Ley, Madrid, 2005, pp. 37-39.

Para un estudio y exposición completa sobre el estado del proceso civil europeo y su evolución, ver esp. Rauscher, Thomas et alt, Europäisches Zivilprozessrecht. Sellier, Múnich, 2006, t. I y II, passim, y Mankowski, PeterMagnus, Ulrich, Brussels I Regulation, European Commentaries on Private International Law, Selllier, Múnich, 2007, pp. 1-69, esp. comentarios a los artículos 38-45 por Konstantinos Kerameus. Partiendo de la visión del mercado comunitario y la necesidad de libre circulación de bienes y servicios y, siendo que la sentencia o un título indubitado continente de un crédito revisten tal calidad (la de un bien), consecuentemente deben eliminarse las barreras para su libre circulación generadas por las asimetrías de los sistemas procesales de los estados miembros. Al respecto, algunos de los pronunciamientos y recomendaciones explícitas de los órganos de la UE para tener en cuenta son: Recomendaciones del Comité de Ministros a los Estados Miembros (No. 84-5), "sobre los principios requeridos en los procedimientos civiles para mejorar el funcionamiento del sistema de justicia", del 28 de febrero de 1984; Consejo Europeo de Tampere de 1999, "Conclusiones de la Presidencia". Estas recomendaciones se concretan en las modificaciones a una convención, y especialmente en un reglamento: Convenio de Bruselas de 1968 "relativo a la competencia judicial y la ejecución de resoluciones judiciales en materia civil y mercantil", modificado por el Reglamento (CE) n 44/2001 del Consejo, de 22 de diciembre de 2000, "relativo a la competencia judicial, el reconocimiento y la ejecución de resoluciones judiciales en materia civil y mercantil". Para detalles sobre el alcance y los ámbitos del convenio, como del reglamento, ver Protocolo $\mathrm{N}^{\mathrm{o}} 1$ "relativo a determinados problemas de competencia, procedimiento y ejecución"; Protocolo No 2 "relativo a la interpretación judicial uniforme del Convenio y al Comité permanente".

Complementan este marco básico el reglamento (CE) n 1346/2000 del Consejo, de 29 de mayo de 2000, "sobre procedimientos de insolvencia"; Reglamento (CE) n 1206/2001 del Consejo, de 28 de mayo de 2001, "relativo a la cooperación entre los órganos jurisdiccionales de los Estados miembros en el ámbito de la obtención de pruebas en materia civil o mercantil"; Reglamento (CE) 2201/2003, "relativo a la competencia, reconocimiento y ejecución de resoluciones judiciales en materia matrimonial y de responsabilidad parental". Finalmente, y partiendo de la aplicación de experiencias en algunos estados miembros como la necesidad de diferenciar áreas simplificadas por no darse contradictorio o por su cuantía, asumen un rol central el Reglamento (CE) $n^{\circ} 805 /$ 2004 del Parlamento Europeo y del Consejo, de 21 de abril de 2004, "por el que se establece un título ejecutivo europeo para créditos no impugnados"; Reglamento (CE) n 861/2007 del Parlamento Europeo y del Consejo, de 11 de julio de 2007, "por el que se establece un proceso europeo de escasa cuantía"; y el Reglamento (CE) n 1896/2006 del Parlamento Europeo y del Consejo, de 12 de diciembre de 2006, "por el que se establece un proceso monitorio europeo". 
Álvaro Pérez Ragone

Oscar Silva Álvarez

oportuno pincelaron y delinearon al proceso civil de fines del siglo XX, el centro de atención se desplaza en el siguiente milenio. Obtener un pronunciamiento sólo con las condiciones antes mencionadas ya no es suficiente, si no puede cumplirse mirando ahora la voluntad e interés del acreedor ${ }^{9}$.

Finalmente, en tercer lugar es posible ver la paulatina constitucionalización de todas las fases del proceso. Desde la de conocimiento - combinada con la cautelar- hasta la ejecución (en los últimos años). Sin embargo, las garantías del pleno contradictorio, debido proceso, y las bondades de la oralidad son imposiciones pensadas y funcionales para la etapa de conocimiento, y no de transplante directo y sin adecuación a la ejecución. Bien puede decirse que ya se superó la visión según la cual executio non est judicandum, sed exequendum y jurisdictio in sola notione consistit. En efecto, jurisdictio sin coertio et executio es norma individual (o sentencia) muerta ${ }^{10}$.

La prohibición de autotutela exige que la jurisdicción, en el ámbito de la ejecución, cuente con los medios idóneos para lograr materialmente lo ordenado, y no sólo identificando la sentencia de condena como el punto final del ejercicio de la jurisdicción ${ }^{11}$. Al Estado se le impone el deber de poner a disposición de los ciudadanos un sistema de ejecución que efectivamente logre la satisfacción del crédito y garantice la seguridad del tráfico ${ }^{12}$. Los

Pueden consultarse también las excelentes exposiciones en el Coloquio Internacional celebrado en 1998 en Paris, "L'Europe Judiciaire: Quelle procédure accélérée de recouvrement des créanses", publicado por la UIHJ, Ed. Juridique et T. , Paris, p. 181; sobre el rol significativo de los distintos órganos de la UE para una mayor eficiencia de la ejecución ver la obra colectiva bajo la dirección de Fricero, Natalie-Isnard, Jacques, La contribution des institutions dans l'aménegment de l'espace de liberté, de securité et de justice, Ed. Juridiques et T, Paris 2006, passim.

9 Guinchard, La garantie, cit. nota n. 1, pp 1015 y ss. La reforma al al art. 1425-1 del NCP Francés del 2004 precisamente puso el centro de atención en el cumplimiento in natura : "Modifié par Décret n`2004-836 du 20 août 2004 - art. 50 JORF 22 août 2004 en vigueur le ler janvier 2005.L'exécution en nature d'une obligation née d'un contrat conclu entre des personnes n'ayant pas toutes la qualité de commerçant peut être demandée au tribunal d'instance lorsque la valeur de la prestation dont l'exécution est réclamée n'excède pas le taux de compétence de cette juridiction. Le juge de proximité est compétent dans les limites définies au code de l'organisation judiciaire et dans les conditions de l'article 847-5 du présent code".

10 Perrot, Roger-Théry, Phillipe, Procédures civiles d'éxécution. Ed. Dalloz, Paris, 2006, p. 9; Leval, George de, Éléments, cit. nota n. 4, pp. 9-23; Crifó, Carla, Cross-Border Enforcement of debts in the European Union. Kluwer Law International, Holanda, 2009, pp. 1-18.

11 Verde, Giovanni, 1999 , “Attualità del principio «nulla executio sine titulo". Riv. Dir. Proc., , pp. 963-988, p. 967; Serra Domínguez, Manuel “Jurisdicción” en Estudios de Derecho procesal, Ariel, Barcelona, 1969, pp. $20-62$.

12 Así especialmente del TEDH se puede ver la Sentencia "Hornsby contra Grecia" de 19 de marzo de 1997 demanda número 18357/91, apartado 40, seguida por la Sentencia "Estima Jorge contra Portugal" de 21 de abril de 1998, demanda número 24550/94, apartado 35. Con posterioridad, los mismos pronunciamientos pueden encontrarse en la Sentencia "Burdov contra Rusia" de 7 de mayo de 2002, demanda número 59498/2000, apartado 34 y Sentencia "Jasiuniene contra Lituania" de 6 de marzo de 2003, demanda número 41510/1998, apartado 27. El Tribunal Constitucional español se ha manifestado sobre la ejecución como relevante en tanto las resoluciones no queden como "meras declaraciones de intenciones sin alcance práctico ni efectividad alguna", o bien "el derecho no pasaría de ser una entidad ilusoria" ( STC 37/2007, de 12 de febrero, FJ 4; STC 145/2006, de 8 de mayo, FJ $3^{\circ}$; STC 86/2006, de 27 de marzo, FJ $2^{\circ}$ ). 
El imperativo de transparencia patrimonial del deudor como requisito funcional para una ejecución civil eficiente The transparency of debtors` assets as a functional requirement for an efficient civil enforcement

principios de necesidad, adecuación y proporcionalidad rigen en la misma forma para ejecutante y ejecutado.

Ahora bien, en la ejecución, a diferencia de la etapa declarativa o de conocimiento, ya no se discute. Las partes procesales son acreedor/ejecutante-deudor/ejecutado, ya que se ejerció una acción ejecutiva fundada en un título indubitado (sea porque surgió de un proceso anterior y tiene la legitimidad procesal para simplemente hacerse cumplir, sea porque la propia ley estableció la misma calidad a determinados títulos extrajudiciales). En consecuencia, desde su nacimiento la ejecución contempla una asimetría intrínseca de las partes frente al derecho sustantivo, estando una de ellas en situación de antijuridicidad y debiendo satisfacer el crédito a la otra. Ignorar esta visión de la ejecución es crear barreras para el pleno funcionamiento del derecho civil como sustantivo. El derecho a una ejecución justa, oportuna y satisfactiva integra, también, el derecho fundamental de acción ${ }^{13}$.

A nivel comunitario en la UE se viene reformulando la visión de la ejecución para poder concretar la satisfacción in natura del crédito. Relevancia especial cobra en las obligaciones de hacer y de no hacer, pero si finalmente debe cumplirse por equivalente (ya no por regla, sino por opción del acreedor) continúa el ejecutado con un deber impuesto, uno de naturaleza procesal de cooperación (es decir, de hacer): transparentar su patrimonio y colaborar para la efectiva satisfacción del crédito, en equivalente. No es otra la finalidad del Libro Verde sobre Efectiva ejecución de resoluciones judiciales en la Unión Europea: la transparencia de los bienes del deudor (COM (2008) 128 final), de 06/03/2008, siendo fruto de las necesidades del tráfico, la reformulación de la tutela ejecutiva de los contratos con el paradigma contemporáneo de UNCITRAL y la influencia innegable de la Convención Internacional de Compraventa de Mercaderías. Se impone, pues, una tutela del derecho sustantivo más eficiente en la faz de ejecución ${ }^{14}$.

Este estudio se divide en ocho secciones. Las primeras tres son introductorias a los principios y elementos generales de la ejecución civil. Pretenden fijar el marco de discusión y los argumentos de base para esbozar el deber de transparencia patrimonial. Éste es tratado en

13 Prevault, Jacques -Vincent, Jean, Voies d'exécution. Mémentos, Paris, 2001, pp. 20-45; Couchez, Gerard, Voies d'exécution, $8^{\mathrm{èm}}$ édition Armand Colin, París, 2005, pp. 12-34; Perrot-Thery, 2006, pp. 10-25 cit. nota n. 10;

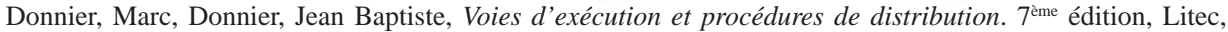
Paris, 2004, pp.30-56; Guinchard, Serge-Moussa, Tony, Droit et pratique des voies d'exécution. Dalloz, París, 2009/2010, pp. 5-25.

14 Sobre el deber de esclarecimiento y transparencia patrimonial en Europa con un detallado estudio comparado ver Holzapfl, Carolin, Sachaufklärung und Zwangsvollstreckung in Europa. Nomos, Baden-Baden, 2008, passim esp. pp. 5-87. La tutela ejecutiva eficiente del crédito ya representaba un problema de política procesal y económica a nivel nacional y comunitario, pero también ofrece enormes complejidades al momento de hablar de derecho procesal civil internacional y ejecución civil internacional, al respecto puede verse Lange, Jérôme, Internationale Rechts-und Forderungspfändung. Duncker \& Humboldt, Berlin, 2004, pp. 17-37. 
Álvaro Pérez Ragone

Oscar Silva Álvarez

detalle en su noción, extensión y alcances personales en la sección cuarta y quinta. Se seguirá con el estado de la cuestión en el derecho positivo chileno, para demostrar que el tema ha merecido cierto tratamiento desigual e insuficiente en muchos casos, por parte del legislador; para completar con una sección séptima donde se analiza someramente el Proyecto de Ley de Código Procesal Civil (PCPC) para Chile. El capítulo octavo está conformado por las conclusiones y propuestas de los autores ${ }^{15}$.

\section{La tutela no efectiva del crédito: el divorcio entre el derecho privado sustantivo y el procesal.}

La abstracción de la acción, lograda por la pandectística alemana y seguida por la doctrina italiana influyente de comienzos del siglo XX, conlleva de forma inherente su pretendida universalidad (y, con ello, quizás una utópica igualdad formal de tutela de los derechos, tributaria de la igualdad con la visión del CC francés de 1804 y del CPC francés de 1806). Solo algunos derechos, como los reales, gozaban de cierto privilegio para ser tutelas in natura, como por ejemplo una acción real reipersecutoria. . Ello era coherente con la falta de técnicas procesales capaces de dar a la acción la efectividad necesaria para alcanzar la tutela específica.

Así, se logró manifestar esa igualdad formal con el proceso declarativo y la sentencia condenatoria y, en todo caso, permitiendo el resultado por equivalente ${ }^{16}$. La sola sentencia de condena ya implicaba la satisfacción del derecho del titular en ella reconocido. La lógica del Código Civil de Napoleón, los arts. 1.142/1144 concebía una íntima relación entre las ideas de abstracción de las personas y de los bienes, de igualdad formal, de autonomía privada y de resarcimiento pecuniario. Ahora, si todos son iguales ante la ley, independientemente de sus diferencias concretas, se debe preservar la libertad como elemento imprescindible para no constreñir la autonomía privada de la voluntad del obligado. Para ello, la tutela resarcitoria por equivalente (y no el cumplimiento específico) se hace ideal, pues, además de igualar el valor del derecho material, no afecta la voluntad del obligado ${ }^{17}$. Dentro de este contexto no resulta ilógico que, aun cuando el obligado pueda cumplir por equivalente, y siendo la alternativa

15 Es curioso si se compara la ambiciosa, quizás, propuesta de los autores, partiendo de un estado de la materia actual y confiado de lege ferenda, con lo percibido y propuesto (aun más ambicioso) ya en el siglo XIX por Trower en el prefacio de su célebre obra The Law of Debtor and Creditor, T. \& J.W. Johnson, Filadelfia, 1861, no queda sino sumarse a sus deseos de modernización de la legislación para una adecuada tutela del crédito.

16 Comp. con un análisis comparativo entre los sistemas del Civil y del Common Law, Ulen, Thomas S., 1984, "The Efficiency of Specific Performance: Toward a Unified Theory of Contract Remedies", 83 Mich. L. Rev., p. 341; Valcke, Catherine, 1996, "The Unhappy Marriage of Corrective and Distributive Justice in the New Civil Code of Quebec”, 46 U. Toronto L.J. , pp. 539, 567.

17 Di Majo, Antonio, La tutela civile dei diritt., Milano, Giuffrè, 1993, p. 156; Mazzamuto, Salvatore, L'attuazione degli obblighi di fare. Jovene, Napoli, 1978, pp. 38-45, p. 198; Marella, Maria Rosaria, La riparazione del danno in forma specifica. Cedam, Padova, 2000, pp. 10-34. 
El imperativo de transparencia patrimonial del deudor como requisito funcional para una ejecución civil eficiente The transparency of debtors` assets as a functional requirement for an efficient civil enforcement

universal el equivalente pecuniario pueda ser ésta su salida aunque incluso no coopera para individualizar sus bienes a realizar si no posee liquidez para ofrecer ${ }^{18}$. Cuando las reglas no son cumplidas, la sanción está en la ineficacia (nulidad o resolución por ejemplo) y en el resarcimiento en dinero, siendo imposible compeler u obligar a cumplir lo que se contrató, aunque esto sea fácticamente posible ${ }^{19}$.

No se obliga al sujeto del contrato a cumplirlo en forma específica, no sólo porque su obligación, como cualquier otra, puede ser expresada en dinero, sino también porque no sería posible, frente a los principios de libertad y defensa de la personalidad, que el juez obligara al contratante a hacer o no hacer ${ }^{20}$. Ahora, si se vinculan el aforismo nemo contra se edere tenetur (como una visión exacerbada de la prohibición de autoincriminación incluso en un ámbito no penal $)^{21}$, con la imposibilidad de exigir en algunos casos el cumplimiento de una prestación de hacer por afectarse la libertad personal, pues menos puede imaginarse una conducta cooperativa impuesta y exigible del deudor para informar sobre su patrimonio (conducta simplemente anexa a la principal exigida). El resarcimiento en dinero, al otorgar un equivalente, mucho más que dar tutela al derecho violado, tiene en vista manejar criterios de mercado, para el cual los ciudadanos son, en esencia, iguales, y difieren sólo en su mayor o menor capacidad competitiva. Así, el legislador termina decidiendo por el acreedor, supliendo su verdadero interés ${ }^{22}$.

Dentro de la regulación de las obligaciones, el Código Civil chileno da énfasis a las obligaciones de dar y, dentro de ellas, las de dar una especie o cuerpo cierto y las dinerarias ${ }^{23}$. Ahora, al regular las fuentes de las obligaciones, considera como la más importante el contrato, pero en lo relativo a los efectos de las obligaciones, separa las consecuencias según su fuente. Así se explicitan los efectos del incumplimiento de una obligación en el art. 1489, lo que sumado a la indiferencia por el tipo de obligación y su cumplimiento dentro de un sistema

18 Un tratamiento crítico de esta visión en la aplicación por parte de las cortes en USA Laycock, Douglas, The death of the irreparable injury rule. Oxford Univ. Press, Oxford, 1991, pp. 5-25, 275-283.

19 Tarzia, Giuseppe, "Vers un concept européen du droit de l'exécution?" en Le droit processuel et le droit de l'exécution, Ed. Juridique et T., paris, 2002, pp. 153-182.

20 Josselin, Jean-Michel- Marciano, Alain, . 2002, "The Making of the French Civil Code: An Economic Interpretation”, 14 Eur. J.L. \& Econ, p. 193; conf. con Spector, Horacio, 2004, "Fairness and welfare from a comparative law perspective”, Chicago-Kent Law Review, pp. 531-539.

21 Un estudio sobre el uso de esta limitación, exageradamente amplia en la tradición continental-europea puede verse Huber, Stefan, Entwicklung transnationaler Modellregeln für Zivilverfahrens. Mohr Siebeck, Tübingen, 2008, pp. 158-169.

22 Comp. Barnett, Randy, 1986, "A Consent Theory of Contract” en 86 Colum L. Rev., p. 269; Benson, Peter, et. Alt., "The Unity of Contract Law", en The theory of Contract Law: New Essays, Cambridge Univ. Press, Cambridge, 2001, pp. 118-120.

23. Véase el original, completo y convincente aporte de Vidal, Álvaro, El Incumplimiento de Obligaciones con Objeto Fungible y los Remedios del Acreedor Afectado en El Código Civil de Chile (1855 - 2005”). Trabajos expuestos en el congreso internacional celebrado para conmemorar su promulgación, Libromar, Santiago, 2007, p. 499. 
Álvaro Pérez Ragone

Oscar Silva Álvarez

(procesal) de ejecución civil, puede hacer concluir que acreedor tiene siempre sólo un remedio explícito, que es la indemnización de perjuicios (cumplimiento por equivalente o pecuniario). Sólo implícitamente pueden vislumbrarse otras alternativas como la ejecución forzada específica, siendo que esta última es la que realmente se condice con la pretensión del acreedor como derecho que emana del solo incumplimiento, y que admite como corolario que la prestación que sustenta su interés sea satisfecha in natura. Esta solución frente al incumplimiento, debería ser la principal, porque eso es lo que al acreedor le interesa.

Por otra parte, en las obligaciones de hacer, el art.1553 del Código Civil Chileno otorga tres opciones al acreedor: ejecución forzada, y dos adicionales por equivalente. Cuando el mismo tema se analiza a la luz del CPC chileno, éste se hace cargo en detalle de los procedimientos de ejecución forzosa de las obligaciones de dar, hacer o no hacer. En éstas últimas distingue si son o no personalísimas, brindando en definitiva la salida del equivalente pecuniario. Es doctrinariamente que se distingue si la obligación de hacer es fungible, o no; ello para que sea el acreedor quien en definitiva opte por dos remedios: la ejecución forzosa y la indemnización de perjuicios, porque podría compeler al deudor a cumplir, aceptar que un tercero realice el hecho o pedir la indemnización de perjuicios. Ahora bien, la visión expuesta funda la calificación de fungibilidad o infungibilidad sobre dos premisas: en primer lugar, se atiende a la específica función de la obligación dentro del tráfico jurídico, y finalmente considera prioritario y decisivo el interés del acreedor que debe ser satisfecho. Coherente con ello, la posibilidad de sustituir o intercambiar su objeto sólo será posible si no se ve lesionada la efectiva satisfacción del interés de la parte, siendo esto el aspecto esencial para determinar la diferencia entre ambos tipos de obligaciones ${ }^{24}$.

La tutela efectiva y específica del crédito se ha desarrollado en Chile principalmente por la doctrina civilista ${ }^{25}$. El tema no mereció la atención de la doctrina procesal, sino apenas con

Ya en la década de los noventa. Ver Chianale, Angelo, Diritto soggettivo e tutela in forma specifica. Giuffrè, Milano, 1999, pp. 155-163; Proto Pisani, Andrea, Lezioni di diritto processuale civile. Juvene, Napoli, 1994, p. 832 y ss.

25 Un resumén de la discusión actual y sus relevancias puede verse en Vidal Olivares, Álvaro, 2009 “ La noción de incumplimiento "esencial" en el código civil", Revista de Derecho de la Pontificia Universidad Católica de Valparaíso_, XXXII, I, pp. 221 - 258. A ello súmesele Barros Bourie, Enrique, "Finalidad y alcance de las acciones y los remedios contractuales”, en Estudios de Derecho Civil III (Coord. Guzmán Brito, Alejandro), Legal Publishing, Santiago, 2008, pp. 406-412; Peña Núñez, B., Ejecución de las obligaciones no dinerarias en el proceso civil, Memoria de Prueba, Universidad de Concepción, 2005, pp. 10-25; Pizarro Wilson, Carlos, "Hacia un sistema de remedios al incumplimiento contractual" (Coord. Guzmán Brito, Alejandro), Legal Publishing, Santiago, 2008, pp. 397-401; Vidal Olivares, Álvaro, "Cumplimiento e incumplimiento contractual en el Código Civil. Una perspectiva más realista" 2007, en Revista Chilena de Derecho nº 34, pp. 48-50; Vidal Olivares, Álvaro, "El incumplimiento de obligaciones con objeto fungible y los remedios del acreedor afectado", Guzmán Brito, Alejandro (editor), El Código Civil de Chile (1855-2005). Trabajos expuestos en el Congreso Internacional celebrado para conmemorar su promulgación, Lexisnexis, Santiago 2007, pp. 532-538. 
El imperativo de transparencia patrimonial del deudor como requisito funcional para una ejecución civil eficiente The transparency of debtors` assets as a functional requirement for an efficient civil enforcement

ocasión del tratamiento de la ejecución de las obligaciones de hacer y no hacer ${ }^{26}$. Es posible entonces sostener la reformulación de los paradigmas de la ejecución, centrándose en la relación entre la satisfacción del interés del acreedor, el cumplimiento in natura y la obligación legalprocesal de cooperación procesal ${ }^{27}$. Este punto de partida permite sostener que el deudor debe primero cumplir bajo la posibilidad de ser sujeto a la ejecución, momento en el cual surge un deber anexo de hacer y no hacer, relacionado con su transparencia patrimonial. Sea que se adhiera a la prelación del cumplimiento in natura, sea que se considere todo traducible en pecunia, el deudor debe cooperar en la ejecución transparentando su patrimonio para lograr la íntegra, plena y oportuna satisfacción del interés del ejecutante.

\section{Requiem a la executio-coertio como elementos de una justicia funcional.}

Es así que convive un sistema sustantivo-procesal que permite al acreedor optar, pero al no establecer un orden de preferencia, curiosamente no se garantiza el cumplimiento específico, que es el que satisface el interés del acreedor. Muy por el contrario, la ejecución en el Código de Procedimiento Civil chileno tiene un sistema de incentivos negativos y positivos que finalizan transfiriendo al deudor la opción y decisión sobre cómo se efectivizará la prestación que se está ejecutando y, por silencio o información incompleta o incorrecta, cuáles serán los activos sobre los que recaerá la agresión ejecutiva. Ahora, si se reunifica la visión sustantiva-procesal de la tutela ejecutiva del crédito como parte del derecho de acción y se reconoce el rol relevante de la función jurisdiccional ejecutiva para la satisfacción específica y los medios para lograrlo, cambian radicalmente los roles de las partes y, especialmente, del ejecutado, quien debe asumir un rol activo. Tanto la ejecución como los órganos predispuestos por el Estado para ejercicio

26 Orellana Torres, Fernando, 2006, "Medios de Impugnación y recursos procesales en la ejecución de condenas no dinerarias" en Ius et Praxis, vol. 12, no. 2, , pp. 163-200; Orellana Torres, Fernando, Procedimiento ejecutivo por obligación de dar. Santiago, Librotecnia, p. 219; Bravo Barahona, A., Procedimiento Ejecutivo en las obligaciones de hacer y de no hacer, Memoria de Prueba, Universidad de Chile, 1930, passim; Espinosa Fuentes, Raúl, Manual de procedimiento civil: el juicio ejecutivo. Editorial Jurídica de Chile, 2003, pp. 10-25; Quinteros Tricot, C, De la ejecución de las obligaciones de hacer y de no hacer, Memoria de Prueba, Universidad de Chile, 1927, passim; Casarino Viterbo, Mario., 1945 "Del cumplimiento o ejecución de las sentencias" en Anales de la Facultad de Derecho XXI, p. . La atención a la ejecución por la doctrina procesal se centra en el último lustro en la sobrecarga de los juzgados civiles y en proponer salidas orgánicas (desjudicializar, que no implica "desjurisdiccionalizar" en un funcionário la actividad ejecutiva sobre un patrimonio (sumas de dinero como prestación debida)) e introducción de una nueva refocalización en el acreedor: Domínguez Balmaceda, Juan Pablo, 2007, "Reflexiones en torno a la propuesta de reforma al Procedimiento Civil Chileno: III. Principios Procesales relativos al Procedimiento" en Revista Chilena de Derecho XXXIV; García José Francisco y Leturia, Francisco Javier. 2006, "Justicia civil: diagnostico, evidencia empírica y lineamientos para una reforma" en Revista Chilena de Derecho XXXIII.

27 Leroy, Étienne, "L'efficacité des procédures judiciaires au sein de l'Union Européenne et les garanties des droits de la défense - Transparence patrimoniale" en L'efficacité de la justice civile en Europe, Larcier, París, 2000, pp. 273-402; Kennett, W. "Aperçus comparatifs des différents modes d'exécution forcée des obligations pecuniaires dans l'Union Européenne”, en Nouveaux droits dans un nouvel espace européen de justice - Le droit processuel et le droit de l'exécution, Ed. Juridique et t., Paris, 2002, pp. 255-265, 264. 
Álvaro Pérez Ragone

Oscar Silva Álvarez

de esta función, tienen un papel protagónico para la tutela efectiva del crédito dentro de las relaciones de circulación del mercado. Si se parte de un deber general de cumplir los mandatos judiciales en las distintas etapas procesales y cualquiera que sea su naturaleza, el sistema procesal debe preveer una serie de mecanismos para tutelar este deber general, sea sancionando su infracción, sea estableciendo herramientas para compeler a su cumplimiento. Por cierto, esta idea ya era vislumbrada por Fueyo Laneri ${ }^{28}$. Con corrección, el autor estimó procedente la aplicación de medidas tendientes a coaccionar sobre la voluntad de quien se niega a cumplir. Con claridad se opuso a la idea de negar aplicación a las medidas coercitivas por el sólo hecho de existir la posibilidad de recurrir a la ejecución forzada. La coerción forma parte de los medios para lograr el cumplimiento paralelamente a la ejecución, y especialmente de deberes procesales. No resulta satisfactorio atribuir a estas medidas un carácter subsidiario. Junto a la necesidad de una adecuada ejecución se vislumbra la necesidad de premunirla de eficacia. Así, las medidas coercitivas toman un rol anexo y necesario para el ejercicio de la función jurisdiccional, especialmente ejecutiva ${ }^{29}$.

En relación a las conductas exigidas dentro de un proceso y que no se identifican con las obligaciones sustantivas, al interés del acreedor se suma la funcionalidad misma del proceso. Por lo tanto, estas conductas serán o no fungibles dependiendo de la necesidad objetiva que tengan para el proceso, sea ésta determinada por el legislador directamente, o habiendo intervenido la labor del juez en su fijación. Como ejecución eficiente implica medios de coerción para su plena funcionalidad: patrimoniales o personales (previsto por cierto en el art. $238 \mathrm{CPC}$ chileno). Siendo que la imposición de una medida coercitiva patrimonial es esencialmente y per se ejecutable, se deben determinar dos temas: uno relacionado con el interés presente en la ejecución de una medida coercitiva, y otro vinculado con la efectiva relación que debe existir entre la finalidad buscada con la imposición de una medida coercitiva de naturaleza patrimonial y el cumplimiento específico de dicha medida, para así arribar al procedimiento más apropiado para lograr dicha ejecución. Es así que, además del interés del acreedor, ahora cobra relevancia el interés público vulnerado por la ofensa a la justicia que implica la desobediencia a sus mandatos. Tutela ejecutiva y específica sin medidas de coerción son inocuas ${ }^{30}$.

Cierto es que la humanización de la ejecución justifica los marcos formales y detallados

28 Fueyo Laneri, Fernando, Cumplimiento e incumplimiento de las obligaciones. Editorial Jurídica de Chile, Santiago, 1992, p. 216.

29 Kerameus, Konstantinos, "Sanctions Against Non-compliance With Enforceability” en Wege zur Globalisierung des Rechts, Beck, Múnich, 1999, pp. 359-375; Aragoneses Martinez, Sara, Las Astreintes. Edersa, Madrid, 1985, pp. 23-35.

$30 \quad$ Fallo del TC chileno sobre el art. 238 CPC del 17 de marzo del 2009, "Municipalidad de Arauco s/ inconstitucionalidad e inaplicabilidad del art. 238 CPC" Rol No 1.145-08-INA, donde a los efectos de validar o no la aplicación del arresto como medida de coerción se acude a la distinción entre obligación derivada de un contrato y obligación legal emanada de una orden judicial. 
El imperativo de transparencia patrimonial del deudor como requisito funcional para una ejecución civil eficiente The transparency of debtors` assets as a functional requirement for an efficient civil enforcement

que encaucen la actividad coercitiva del Estado en la jurisdicción ejecutiva, con el fin de resguardar los derechos fundamentales del deudor. No obstante, esto es aceptable en la medida que, para la protección de la dignidad del ejecutado, no se ofenda la dignidad de la otra parte, como ciudadano que busca el restablecimiento de sus derechos violados. Los principios de idoneidad, adecuación y proporcionalidad rigen para ambos extremos, y su correcto establecimiento legislativo no resulta sencillo. El proceso se debe estructurar de manera técnicamente idónea para permitir la prestación de las formas de tutela prometidas por el derecho material. De este modo, entre la tutela de los derechos y las técnicas procesales debe haber una relación de adecuación. Pero esa relación de adecuación no se refiere ya a las formas de tutela, sino a las técnicas procesales. La prioridad del cumplimiento específico y la necesidad de una tutela ejecutiva de dicha posición de crédito surgen del propio derecho material. En realidad, si el lesionado tiene un derecho, le cabe escoger la forma de reparación, que puede ser específica o por equivalente. Así por ejemplo, en la obligación contractual puede decirse que el contrato produce sus efectos normales o previamente deseados. El acreedor cree en el normal desarrollo de la relación, según la obligación de las partes y la función económica tenida en vista en el momento inicial. El pago del equivalente, como respuesta jurisdiccional al incumplimiento de la obligación contractual, supone la obligación como un poder del acreedor sobre el patrimonio del deudor, y no la obligación como un derecho a la prestación ${ }^{31}$.

Ahora bien, una inadecuada concepción de la ejecución ha llevado a que, en la práctica, ésta se entrampe en una, a veces, exagerada discusión, como si estuviésemos frente a un procedimiento declarativo. Ello ha hecho olvidar que, a diferencia de la etapa declarativa o de conocimiento, en la ejecución ya no se discute, o la controversia debe ser reducida a su mínima y esencial expresión ${ }^{32}$. Las partes procesales son acreedor/ejecutante y deudor/ejecutado, ya que se parte de un título indubitado (sea porque surgió de un proceso anterior y tiene la legitimidad procesal para simplemente hacerse cumplir, sea porque la propia ley estableció la misma calidad a determinados títulos) lo que genera una natural asimetría de las partes. Ello de tal suerte que una de ellas está en situación de antijuridicidad y debe satisfacer el crédito a la otra, sin que quepa discusión, sino sólo ejecución. . Ignorar esta visión de la ejecución en la más elemental de sus finalidades es fomentar la crisis del derecho sustantivo ${ }^{33}$.

Sin embargo, es necesario aclarar que el problema de la discusión en la ejecución es tan sólo una de las aristas de las múltiples que podemos encontrar en esta etapa de la jurisdicción. Por ello quizás se trata de un aspecto cuyo mejoramiento puede depositarse, casi íntegramente, en manos de un legislador más conciente en esta materia, y que reglamente la ejecución con

\footnotetext{
31 Tarzia, Giuseppe, 2002, "Il giusto processo di esecuzione" en Riv. Dir. Proc., pp. 329-350 (esp. pp. 330-331)

32 Andolina, Italo, Cognición y ejecución forzada en el sistema de la tutela jurisdiccional Communitas. Lima, 2008, pp. 85-110.

33 Andolina, cit. nota n. 32, pp. 85-110.
} 
énfasis en su naturaleza no declarativa, sin que ello suponga cercenar las posibilidades legítimas de defensa del ejecutado, pero entendiéndola como una situación anormal en el contexto de la realización de un título que da cuenta, en principio, de un derecho indiscutido a favor de una persona $^{34}$.

Teniendo presente lo antes mencionado, el presente artículo tiene por objeto presentar un problema y el abanico de soluciones doctrinales y de derecho comparado al respecto. Se parte desde la óptica sustantiva de la obligación y los deberes que asume el deudor por un lado en relación a la satisfacción del crédito ${ }^{35}$. Consideramos que uno de estos deberes integra la eventual relación procesal-ejecutiva de transpariencia patrimonial (un deber de naturaleza procesalsustantivo $)^{36}$.

\section{Concepto y función de una ejecución como momento y punto de inflexión de la jurisdicción.}

En la ejecución se efectivizan las pretensiones del acreedor contra el deudor, mediante la coerción estatal. Únicamente puede tener lugar en función de una prestación, esto es, una obligación de pago, de hacer, no hacer, tolerar o de emitir una declaración de voluntad. Se funda sobre una sentencia que, parcial o totalmente, contenga una condena ${ }^{37}$, o bien sobre determinados títulos asimilables a la sentencia, y que son establecidos por el legislador. La sentencia condenatoria que impone una prestación habilita para que el vencedor (ahora acreedor) pueda requerir la ejecución en caso de incumplimiento. Como es obvio, la ejecución solamente es necesaria cuando la condena no es cumplida voluntariamente. O sea, la sentencia de condena, al determinar declarando que debe cumplirse con un deber, ya prevé la posibilidad de su propio incumplimiento, conformándose los presupuestos que viabilizan su ejecución. En razón de la sentencia condenatoria, la jurisdicción queda autorizada a practicar actos ejecutivos. El otrora actor, ahora acreedor/ejecutante, queda investido del poder de requerir la ejecución, y el otrora demandado, ahora deudor/ejecutado, queda sometido al poder ejecutivo de la jurisdicción. La sentencia condenatoria, en principio, permite el cumplimiento de un hacer, de no hacer, de entrega de cosa y de pago de suma y se vincula por regla, a los medios de ejecución que

34 Andolina cit. nota n. 32, pp. 85-110.

35 Así Schnigula, Jörg, Das Offenbarungsverfahren-Darstellung und Reform der Sachaufklärung in der Zwangsvollstreckung. Gardez Verlag, 2002, pp. 68-75.

36 En cierta medida no hacemos sino aplicar el deber general que pesa sobre las partes procesales de cooperar con el esclarecimiento y dinámica del proceso, aplicamos por analogía estos postulados de stürner a la ejecución, donde a fortiori al menos la transparencia del patrimonio del ejecutado constituye un dato relevante para la suerte de la propia ejecución, ver Stürner, Rolf, Die Aufklärungspflicht der Parteien des Zivilprozesses. Mohr, Tübingen, 1976, pp. 300-325.

37 Rosenberg, Leo-Gaul, Hans-Schilken, Eberhard, Zwangsvollstreckungsrecht München. Ed. C.H. Beck, 1997 $\S 1$, I, pp. 1 - 7; Prütting, Hans -Stickelbrock, Barbara, Zwangsvollstreckungsrecht. Ed. Boorberg, Stuttgart, 2002, pp. $29-30$. 
El imperativo de transparencia patrimonial del deudor como requisito funcional para una ejecución civil eficiente The transparency of debtors` assets as a functional requirement for an efficient civil enforcement

permiten la realización del derecho de crédito a través de la orden de disposición de activos ya líquidos (pago de dinero) o la venta y liquidación forzosa judicial de bienes del patrimonio del deudor. Actualmente, la sentencia condenatoria no está predispuesta para la tutela específica que necesita de la imposición de un no hacer, hacer o de entrega de una $\cos ^{38}$.

Pero incluso no sirve el cumplimiento de una obligación contractual de hacer o de entregar una cosa, especialmente para la tutela específica de los derechos que exigen una actuar preventivo antes que sancionador o correctivo, ya que precisamente se tiende a evitar un dañar (por ejemplo en la tutela de derechos de la personalidad o ambientales). La tutela por el equivalente y la tutela específica de la obligación de pagar en dinero son prestadas por una sentencia que se conecta a medios de ejecución tipificados en el CPC chileno. Ya que la tutela específica requiere la imposición de un no hacer y de un hacer, constituyen auténticas normas procesales abiertas. Esas normas sólo instituyen técnicas procesales, sin vincularlas a las situaciones de derecho sustancial determinadas. Por lo tanto, están lejos de pretender obligar el acreedor al equivalente. $\mathrm{Al}$ contrario, su intención es ofrecer un abanico de instrumentos procesales o un arsenal de herramientas, dejando su uso a criterio del justiciable y del juez ${ }^{39}$. Este abanico incluye el escenario último de una obligación derivada en pecuniaria, en que se tenga conocimiento del patrimonio sobre el que se ejercerá la agresión del acreedor.

Refiriéndonos específicamente a la a ejecución fundada en prestaciones dinerarias, ésta es, a su vez, subdivisible de acuerdo con los bienes patrimoniales del deudor sujetos a ella y que puedan ser agredidos, es decir: cosas muebles, créditos y otros derechos patrimoniales y bienes inmuebles ${ }^{40}$.

Desde este punto de vista, el derecho de la ejecución se caracteriza por una relación de agresión patrimonial en la esfera del requerido (deudor), sobre la base de una petición del requirente (acreedor). $\mathrm{Y}$ es debido a esta posible afectación de importantes derechos fundamentales, desde el derecho de propiedad hasta la libertad personal, que la ejecución se encuentra no sólo regulada en detalle, sino sometida a principios tan importantes como el de formalidad $^{41}$.

38 Tommaseo, Ferrucio, "Sull'Attuazione dei Diritti di Credito nell'Esecuzione in Forma Specifica" en Studi in Onore di Enrico Tullio Liebman. Giuffrè, Milano, vol. III, 1979, p. 2421 y ss.; Wambier, T. (coords.) Execução Civil: Estudos em Homenagem ao Professor Humberto Theodoro Júnior, São Paulo: RT, 2007, pp. 34-67; Monteleone, Girolamo "Riflessioni sulla Tutela Esecutiva dei Diritti di Credito" In: Studi in Onore di Enrico Tullio Liebman. Giuffrè, Milano, vol. III, 1979, p. 2257 y ss.

39 De Oliveira, Carlos Alberto Alvaro, 2005 "Formas de tutela jurisdicional no chamado processo de conhecimento" en Revista Ajuris, , 100,59-72, esp. p. 69-71.

40 Hernandez, La ejecución judicial y sus alternativas en España y México. Ed. J. M. Bosch, Barcelona, 2008, pp. 15-35.

41 Stürner, Rolf, 1986, "Prinzipien der Einzelzwangsvollstreckung” en Zeitschrift für Zivilprozessrecht (ZZP) N 99, p. 291; Gaul , Hans, 1999, "Rechtsverwirklichung durch Zwangsvollstreckung aus rechtsgrundsätzlicher und rechtsdogmatischer Sicht", en ZZP, N 112, p. 135. 
Álvaro Pérez Ragone

Oscar Silva Álvarez

Doctrinalmente, puede afirmarse que los sujetos que intervienen en la ejecución son, por un lado, los órganos de ejecución (que no se reducen únicamente a un tribunal de ejecución) y, por otro, las partes (acreedor y deudor) y los terceros. Los dos primeros son necesarios, mientras los últimos no.

\section{1- Órganos.}

Los órganos de ejecución llevan a cabo las distintas medidas de ejecución a instancias del acreedor, con base en la distribución de la competencia funcional. En este ámbito, pensar en un oficial de ejecución, como un ente de ejecución externa que desempeña las funciones atinentes a la notificación, citación y medidas de ejecución propiamente tales, es una alternativa válida para una tarea desjudicializada, aunque seguimos hablando de una función estatal jurisdiccional. Este funcionario bien puede intervenir teniendo a su cargo la ejecución con base en pretensiones dinerarias, para la realización del embargo, la efectivización de la prenda judicial de cosas muebles y la ejecución de prestaciones de restitución de cosas, y está autorizado para ser auxiliado por la fuerza pública ${ }^{42}$.

Esta institución no debe sorprendernos en demasía, como si fuese absolutamente ajena a nuestro ordenamiento jurídico. En efecto, de alguna manera, esta función hoy es ejercida, aunque con un carácter menos técnico, por los receptores judiciales, y con un carácter más técnico, como en el caso de los síndicos en la quiebra. Incluso, la fuerza de las cosas ha hecho que, bajo formas nuevas de procedimientos ejecutivos su figura siga teniendo relevancia práctica en cuanto agente de ejecución, como ocurre con la ejecución bajo la ley de reforma procesal laboral, que es bastante débil en cuanto reglamentar, con precisión, la manera de proceder a la ejecución, cuestión que es muy criticable.

Otro órgano de ejecución -el más importante- es el tribunal de ejecución, de actuación paralela al funcionario antes mencionado. Como tal, se desempeña el juzgado en cuyo territorio jurisdiccional tiene lugar el proceso de ejecución. Sin embargo, conviene poner en relieve el rol contralor que debe ejercer el tribunal, en cuanto vele por el respeto de los procedimientos concretos de ejecución y de las garantías fundamentales de las partes intervinientes (fundamentalmente del ejecutado). Sin embargo, se trata de un rol que, a diferencia de lo que ocurre en la etapa declarativa, debe ser, por una parte, limitada y, por otra, eventual ${ }^{43}$.

42 Para una presentación detallada y comparada dentro de la UE puede verse la obra colectiva con las relatorías de cada país de la UE en Les professionnels de la signification et de l'exécution en Europe, Ed. Juridiques et t., Paris, 2006, passim.

43 Guinot, Thierry, L'huissier de Justice: Normes et Valeurs, Ed. Juridiques et t., Paris, 2004, pp. 285-373; conf. con el modelo alemán pero en el mismo sentido de desjudicialización Urte, Nesemann, 2006, “Gerichtsvollzieher in Vergangenheit und Zukunft” en Zeitschrift für Zivilprozess (ZZP), No 119, pp. 87-108. 
El imperativo de transparencia patrimonial del deudor como requisito funcional para una ejecución civil eficiente The transparency of debtors` assets as a functional requirement for an efficient civil enforcement

Limitada, en cuanto la ejecución, como etapa en la que la jurisdicción tiene poco que decir en cuanto al establecimiento del derecho efectivizado (precisamente porque éste es ejecutado). Eventual, en cuanto su intervención está sujeta, fundamentalmente, al requerimiento que realice el ejecutado, sea para la oposición de las excepciones pertinentes en contra de la ejecución, o bien para su pronunciamiento respecto a conflictos que se susciten respecto a determinadas medidas ejecutivas.

Nuevamente podemos encontrar estos rasgos presentes en nuestro CPC, en cuanto, si bien existe una demanda ejecutiva y un control previo efectuado por el tribunal, su intervención posterior estará circunscrita a supervisar los trámites del apremio, salvo que el ejecutado decida judicializar el procedimiento, mediante la oposición de excepciones.

En cuanto a otros órganos, los distintos operadores del sistema registral, tales como el Conservador de bienes raíces y el Registro Civil, desempeñan también un rol importante en la publicidad de las distintas medidas de agresión o conservación patrimonial, lo que tiene importancia, en algunos casos, para sacar del comercio humano determinados bienes (fundamentalmente inmuebles) y, en otros, para presumir el conocimiento (y, sobre esa base, poder acreditar la mala fe) de terceros adquirentes de bienes del deudor de la existencia de medidas ejecutivas, como un embargo.

Como puede verse, no existe un solo órgano que intervenga en la ejecución, sino varios posibles, que actuarán según la pretensión a ejecutar, el objeto asiento de agresión y las medidas ejecutivas a realizarse. Esta intervención diferenciada de órganos competentes que puede ser escindida conceptualmente no es sino una aplicación de la necesaria formalidad a la que está sujeta la ejecución; formalidad que no debe en ningún caso interpretarse como "formalismo". La formalidad adecuada coadyuva a la trasparencia y eficiencia, especialmente en la ejecución, donde por un lado se debe velar por la satisfacción de un interés crediticio, pero, por el otro, ello debe hacerse con el auxilio del Estado, respetando los derechos fundamentales del ejecutado ${ }^{44}$.

\section{2- Las partes y los terceros.}

El sujeto interviniente en la ejecución, que posee una pretensión titularizada cuya ejecución solicita, es el acreedor. Éste es el dueño del proceso de ejecución, donde rige al máximo el principio dispositivo. El deudor es la otra parte, es decir, contra quien se realiza la ejecución; es quien figura como obligado en la pretensión contenida en el título y está en una posición susceptible de ser agredido patrimonialmente. Así, es acreedor ejecutante aquel para el cual el título es ejecutable, mientras que deudor ejecutado es aquel contra el cual el título se ejecuta ${ }^{45}$. 
Los otros sujetos de la ejecución son los terceros, aunque con un carácter eventual. En primer término, tenemos al tercero deudor (respecto del cual el deudor ejecutado es acreedor), que interviene en los casos en los cuales la ejecución de una pretensión dineraria no se reduce a la relación entre el acreedor y deudor. Así, se le podrá prohibir que efectúe un pago al deudor ejecutado, reglamentando la manera de evitar que este tercero pueda, en conjunto con el deudor ejecutado, realizar maniobras fraudulentas destinadas a evitar el cumplimiento de dicha orden.

Aparte del tercero deudor es posible que existan otras personas cuyos derechos patrimoniales pueden verse afectados por la actividad ejecutiva que desempeña el órgano de ejecución sobre el patrimonio del deudor. Ello da lugar a lo que se conoce como tercerías, dentro de las cuales podemos encontrar aquellas relativas al pago (preferencia o concurrencia en él) y otras que pretenden sustraer de los bienes embargados determinados bienes, aparentemente pertenecientes al deudor, pero que se sostiene no ser así (dominio y posesión).

En este acápite nos encontramos ante un punto extremadamente sensible de cara a la efectividad de la ejecución. En efecto, es conocida en la práctica el ejercicio abusivo, y en ocasiones fraudulento, de estas acciones, con el fin directo de disminuir el patrimonio ejecutable del deudor. Ello se vincula, entre otras razones, con la falta de instrumentos que permitan singularizar, con seguridad, el patrimonio ejecutable del deudor.

Pero no se agotan allí los posibles terceros relevantes para la ejecución. En el mismo plano, deben ubicarse aquellos que, en su rol dentro de las relaciones con el ejecutado, tienen parte de ese acervo patrimonial que pueda servir para la satisfacción del crédito del ejecutante, o bien cuentan con información útil para poder localizar dicho acervo ${ }^{46}$. Todos estos terceros tienen un deber de cooperación con el Estado en la función jurisdiccional ejecutiva. Es claro que debe sopesarse su relación sustantiva con el deudor frente a la relación procesal de cooperación, sin embargo, ello nunca podría traducirse en un desmedro de la eficacia de la ejecución ${ }^{47}$.

\section{3- Sobre qué se ejecuta: La existencia de bienes sobre los cuales satisfacer el crédito.}

Importante doctrina ha llegado a afirmar que existe un principio de adecuación de la ejecución a sus objetivos, que exige, entre otras cosas: a) que se pongan a disposición del ejecutante los instrumentos necesarios para la identificación de bienes embargables; y b) que permitan el logro del fin al que están destinados ${ }^{48}$. El TCE, por su parte, se ha manifestado

46 Un estudio detallado con énfasis en el Derecho Concursal, pero de aplicación a la ejecución individual puede verse en Heese, Michael, Gläubigerinformation in der Insolvenz. Ed. Mohr Siebeck,Tübingen, 2008, pp. 10 - 47.

47 De Oliveira, Formas cit. nota n. 39, pp. $69-71$.

48 Fricéro, Natalie, "Les exigeance actuelles du droit européen: une execution effective et humaine” en L'exécution immobilière en Europe. Entre Tradition et modernité, Editions J. et T., Paris, 2005, pp. 9-19; Tarzia, Guiseppe, 2002, "Il giusto processo di esecuzione", Rivista di Diritto Processuale, complemento al n. 4, pp. 330 - 331. 
El imperativo de transparencia patrimonial del deudor como requisito funcional para una ejecución civil eficiente

The transparency of debtors` assets as a functional requirement for an efficient civil enforcement

sobre la relevancia de estos mecanismos en la ejecución, a fin que las resoluciones judiciales de condena no queden reducidas a "meras declaraciones de intenciones sin alcance práctico ni efectividad alguna", con lo que "el derecho no pasaría de ser una entidad ilusoria" 49 .

Por lo demás, la prohibición de autotutela exige que la jurisdicción, en el ámbito de la ejecución, cuente con los medios idóneos para lograr materialmente lo ordenado por el fallo, sin identificar la sentencia de condena como el punto final del ejercicio de la jurisdicción ${ }^{50}$.

Precisamente dentro de este ámbito, vale la pena abordar un tema históricamente relegado por la doctrina procesal iberoamericana, pero fundamental de cara a la obtención de los fines de la jurisdicción. Nos referimos a la transparencia patrimonial de los deudores.

\section{La transparencia patrimonial del deudor en la ejecución.}

Una primera aproximación dogmática al objeto de nuestro estudio revela un problema terminológico, derivado de la utilización indiscriminada, incluso por los mismos autores, de palabras distintas para referirse a qué se procura conocer sobre el patrimonio del ejecutado: búsqueda, descubrimiento, localización, selección, fase de localización, elección, individualización ${ }^{51}$, etc.

Así, en pos de la generación de una coherencia terminológica y semántica, corresponde distinguir, por una parte, la investigación de datos relativos al deudor/ejecutado, dentro de los cuales se encuentra la información patrimonial. En este ámbito, debe tenerse presente la natural posibilidad que una investigación patrimonial conduzca a no encontrar bienes, sea porque no tenga, o quizás porque el deudor, intencionalmente, los ocultó o los enajenó. Si se sancionan esas conductas penal o sólo civilmente (inoponibilidad o nulidad), es materia de política procesal y con alta incidencia en la efectividad del imperativo de transparencia patrimonial.

Sin embargo, incluso con resultados positivos en la investigación patrimonial del deudor, pueden subsistir algunos problemas. En efecto, un segundo obstáculo, ya con bienes localizados, Ramos Francisco, Derecho y processo. Ed. Bosch, Gerona, 1979 p. 277; Serra, cit. nota n. 11, pp. 20 - 32. Así, para Comoglio, la individualización tanto puede consistir en la identificación material o espacial de bienes como en la identificación jurídica u ontológica de bienes embargables, (equivalente a la determinación de su aptitud jurídica abstracta para ser embargados). Comoglio, Luigi.1992. "L'individuazione dei beni da pignorare", Rivista di Diritto Processuale XLVII (segunda serie), n. 1, pp. 83 - 134. Le sigue Merlin, "L'individuazione", cit. nota n. 4, pp. 205 - 228. Comp. por cierto con Satta, Salvatore. 1965, "La ricerca delle cose da pignorare", Rivista Trimestrale di Diritto e Procedura Civile XIX p. 151; Satta, Salvatore, Cose e beni nell'esecuzione forzata, en: Soliloqui e colloqui di un giurista , Padova, Ed. CEDAM, Padova, 1968, p. 361; para un estudio detallado Holzapfl, Sachaufklärung cit. Nota n 14, pp. 90-110. 
es que estos deben ser aptos para satisfacer el crédito del ejecutante, lo que no ocurre, por ejemplo, con los bienes inembargables, aquellos imposibles de ser realizados ${ }^{52}$ o aquellos cuya utilidad de realización es marginal, en relación a los costos que supone administrar y vender dichos bienes, como ocurre con la intervención de un martillero público, en donde es frecuente encontrar remates donde el saldo a pagar al ejecutante alcanza cifras irrisorias.

Ahora bien, lograr acceder a una información adecuada es un objetivo que puede conseguirse por varios medios, y distribuyendo los costos e impulsos en los distintos sujetos de la ejecución.

Una de esas alternativas es acudir al propio ejecutado (tal como podría afirmarse que ocurre en el sistema chileno actual), como quien mejor conoce su patrimonio. En esta posibilidad, un primer aspecto a esclarecer, y que abre atractivos caminos de investigación, consiste en la confrontación que puede producirse entre el derecho al silencio (como manifestación de la tutela de la libertad moral del individuo), por una parte, y el deber de colaboración, por otra. En efecto, puede debatirse acerca de la eventual ampliación de la prohibición de autoincriminación, propia de materias penales ${ }^{53}$, a la esfera del derecho civil.

Debe asumirse que la instauración de mecanismos que propendan a obtener una sincera declaración del deudor supondrá, en mayor o menor medida, y a veces de forma extremadamente sutil, su punibilidad por la reticencia a colaborar, aunque se encuentre revestida en forma de apremio. Y nos referimos a la posibilidad de apremios en general, sin perjuicio de los límites que puedan establecer los TTII de DDHH y nuestra concepción cultural, que tiene cierta reticencia frente a determinados apremios (sobre todo que afecten la libertad del sujeto) para la búsqueda de la verdad en el proceso. Sin embargo, una visión que, de manera simplista e irreflexiva, proscribe toda posibilidad de apremiar al renuente, implica desproteger, palmariamente, el derecho de crédito; y lo que es peor aún: olvidar que el silencio, en ocasiones, supone la afectación insubsanable del derecho del acreedor.

Una segunda alternativa teórica en materia de acceso a la información puede consistir en acudir a terceras personas, vinculadas de alguna manera con el patrimonio del deudor, sea actualmente o bien en el pasado ${ }^{54}$. Bajo esta hipótesis, la transparencia patrimonial hace

Leroy, L'efficacité, cit. nota n. 27, pp. 273 - 402; ver al respecto la obra colectiva de Verberke, Alain, MarieThérese, La transparence patrimoniale, condition nécessaire et insuffisante du titre conservatoire Européen?. Ed. Juridique et technique, Paris, 1999, pp. 9-76, 547 p.

53 Un interesante planteamiento puede observarse en Amodio, Enrico.1974. "Diritto al silenzio o devere di colaborazione?", Rivista di Diritto Processuale XXIX (II serie), n. 31974 pp. 418 - 419.

54 En detalle ver el estudio de Hess (2004). Igualmente comp. Comisión de las Comunidades Europeas (2008), en que se señala que "la eficacia de las vías de ejecución en la Unión Europea exige una acción coordinada", añadiendo que "la Comisión estima oportuno reflexionar, habida cuenta del interés que presenta el sistema, 
El imperativo de transparencia patrimonial del deudor como requisito funcional para una ejecución civil eficiente

The transparency of debtors` assets as a functional requirement for an efficient civil enforcement

necesario partir de lo público y de la información de acceso posible para todo eventual interesado, en cuanto ésta sea relevante y necesaria para configurar el mapa del estado patrimonial del ejecutado. Ello supone abarcar varios aspectos íntimamente vinculados entre sí: a) el domicilio del ejecutado, b) el activo patrimonial del ejecutado y c) el pasivo patrimonial del ejecutado ${ }^{55}$.

En este campo, nuevamente vale la pena cuestionarse acerca del rol instrumental de la coerción para lograr la ejecución, lo que implica, a su vez, tener presente el principio de proporcionalidad de los medios utilizados, en tanto agreden patrimonialmente al ejecutado y pueden afectar diversos derechos fundamentales del mismo, aunque deba guiar la actividad ejecutiva el derecho fundamental del acreedor a la tutela judicial efectiva. Este equilibrio, en todo caso, es bastante difícil de lograr al momento de intentar plasmarlo en normas positivas, sobre todo cuando se trata, en este caso, de imponer deberes de conducta a terceros.

Carnelutti enseña, que no es suficiente para el éxito del proceso ejecutivo, que el patrimonio del deudor exista y sea conservado. A ello debe agregarse, además, que se trate de un patrimonio ostensible (entiéndase en relación con la acreencia). Si los bienes existen y pertenecen al deudor, pero resulta imposible acceder a estos para el acreedor, es como si no hubiera nada. Por ende, el sistema procesal debe preveer el peligro de la ocultación o distracción patrimonial, que pueden ser realizadas por el deudor o por terceros, que obstaculizan la dinámica ejecutiva. Así como en la etapa de conocimiento la posibilidad coercitiva existe en contra el testigo que rehúsa comparecer, o respecto del confesante que no comparece a la audiencia de absolución de posiciones o da respuestas evasivas, con mucha mayor razón deben instaurarse deberes y sanciones efectivas frente a la inconducta procesal en la ejecución ${ }^{56}$.

Así las cosas, es posible afirmar que el éxito de la ejecución depende, en gran medida, de la técnica legislativa procesal que viabilice la investigación patrimonial y genere incentivos negativos y positivos para lograr una adecuada transparencia patrimonial del ejecutado. En tal sentido, relacionando la jurisprudencia del TEDH en materia de derecho a la ejecución con la

sobre la generalización de la obligación de declaración de patrimonio como medio de localizar los elementos activos y pasivos de éste". Ya indicando la necesidad del trabajo coordinado de los estados miembros al respecto véase Verbeke, Alain-Caupain, Marie-Thérèse, La transparence patrimoniale, Condition nécessaire et insuffisante du titre conservatoire européen?, Edition J. et T. , Paris, 2001, pp. 35-42.

55 Kennett, Wendy, Aperçus comparatifs des différents modes d'exécution forcée des obligations pecuniaires dans l'Union Européenne, en Nouveaux droits dans un nouvel espace européen de justice - Le droit processuel et le droit de l'exécution, Ed. Juridiques et techniques, París 2002 p. 264. Comp. por cierto los detalles en este sitio con registros para la ponderación del riesgo comercial en el tráfico Business Register Interoperability Throughout Europe: http://www.briteproject.net (visitado 7.7.2009) 
eficacia de la investigación y transparencia patrimonial, es posible reafirmar el importante y delicado rol del legislador en esta materia ${ }^{57}$.

\section{1- El deber de transparencia como corolario del principio de cooperación (procesal) en la ejecución.}

Resulta en ocasiones sorprendente observar cómo en nuestra legislación y, consecuentemente, en la práctica, se deja de lado la tarea de equilibrar la protección de los distintos intereses que concurren en la ejecución civil, para concentrarse, fundamentalmente, en la protección de los derechos del deudor ${ }^{58}$. Aspectos como la ocultación de bienes, el abuso en la generación de estructuras jurídicas para difuminar el patrimonio (como las conocidas sociedades de papel), la aplicación incorrecta de las normas sobre secreto bancario, la timidez en la aplicación de vinculación de datos en línea y la deficiente aplicación de medidas coercitivas y sanciones ${ }^{59}$, son incompatibles con los derechos fundamentales y la protección del acreedor en la ejecución civil. No sólo se ofenden y afectan los derechos del acreedor/ejecutante, sino que se burla el óptimo funcionamiento de la jurisdicción ${ }^{60}$.

El derecho fundamental a la tutela judicial efectiva, oportuna y adecuada y el derecho fundamental a la dignidad humana, se ven inmediatamente agredidos, incluso en forma más evidente que una dilación temporal en un juicio declarativo. En efecto, el acreedor con un derecho indiscutido debe, aún, controlar y verificar dónde y cuándo ejecutar. Sin posibilidad de objeto patrimonial a agredir, ese título sigue siendo (y finalmente será) una promesa incumplida del sistema jurídico procesal, en evidente contradicción con el derecho sustantivo. Es ésta la raíz de la relevancia del tópico.

\section{2- Los datos relevantes en la transparencia patrimonial.}

La búsqueda del domicilio del deudor es, a menudo, el punto de inicio del procedimiento de ejecución, y constituye un dato de importancia incluso mayor que en la etapa declarativa, toda vez que el domicilio será, frecuentemente, uno de los primeros lugares en los cuales se

Así, especialmente, sentencia "Hornsby contra Grecia”, de 19 de marzo de 1997, demanda número 18357/91, apartado 40; seguida por la sentencia "Estima, Jorge contra Portugal”, de 21 de abril de 1998, demanda número 24550/94, apartado 35. Con posterioridad, los mismos pronunciamientos pueden encontrarse en la Sentencia "Burdov contra Rusia", de 7 de mayo de 2002, demanda número 59498/2000, apartado 34, y sentencia “Jasiuniene contra Lituania", de 6 de marzo de 2003, demanda número 41510/1998, apartado 27.

58 Sbert Perez, Héctor Sebastián, La Investigación del patrimonio del ejecutado, (Tesis doctoral U. Pompeu Fabra), 2008 (2008) pp. 33-58.

59 Solove, Daniel J. , "The Virtues of Knowing Less: Justifying Privacy Protections against Disclosure”, Duke Law Journal, Vol. 53, No. 3, 2003 pp. 967-1065.

60 Ya se expresaba en el mismo sentido antes de las grandes reformas en Europa martens (1992), "L'irrésistible ascension du principe du proporcionnalité”, Homenaje Mélanges a Velu, tomo I Bruxelas, Bruylant, pp. 49-68. 
El imperativo de transparencia patrimonial del deudor como requisito funcional para una ejecución civil eficiente

The transparency of debtors` assets as a functional requirement for an efficient civil enforcement

averiguará la existencia de bienes. Sería así deseable que se contemplara una obligación de información para el ejecutado, dentro del procedimiento ejecutivo, con el fin de evitar litigar con un deudor fugitivo, e involucrarlo tempranamente, con un antecedente directo para poder ubicar bienes embargables ${ }^{61}$.

Sin embargo, es cierto que, en la mayoría de los casos, el acreedor ya sabe la dirección del deudor, ya sea porque tiene relación contractual con éste o porque ya fue, otrora, su demandado, pero no siempre la dirección es un dato simple de obtener. Allí es donde comienza el rol cooperativo de determinados terceros, siempre que ello esté adecuadamente regulado y que el deudor no colabore en dicho esclarecimiento.

La funcionalidad de la información aislada del Registro Civil (incluyendo el Registro Nacional de vehículos motorizados), del Servicio de Impuestos Internos, de los Conservadores de bienes raíces, de las Direcciones de Tránsito municipales (en materia de licencias de conducir), entre otros organismos públicos, no suele conducir a resultados óptimos, aunque sí la información cruzada de todas las fuentes disponibles.

Superado este primer obstáculo, debe avanzarse hacia la obtención de información sobre bienes sobre los cuales se ha de ejercer el derecho de ejecución y agresión patrimonial mediatizada por el Estado, donde la situación es similar ${ }^{62}$.

Como simple anécdota del proceso civil comparado, mientras en Inglaterra el abanico de posibilidades para ordenar el cumplimiento de este deber de transparencia por el deudor y terceros es amplio; al igual que en Luxemburgo y Alemania, donde el acreedor puede obtener información de terceros sobre la base de decisiones "mandamentales" provisorias, e incluso de títulos ejecutivos provisorios ${ }^{63}$; en otros países, como España, las limitaciones y centralización de la actividad en el tribunal -parcialmente desdoblado en el secretario- y la necesidad de una actuación fundada del juez no facilitan la tarea de acceso a la información.

En esta parte del camino que debe seguir el acreedor, cobra importancia el acervo de información con que cuentan terceras personas. Primeramente, debe tenerse presente que, fuera del procedimiento de ejecución, los terceros no están obligados a revelar información acerca de la situación financiera del deudor. Incluso, en el hecho, las diversas manifestaciones del

61 Verberke, La transparence, cit. nota n. 52, pp. 9-76, 547; comp. Hippler, Robert, Vermögensoffenbarung, eidesstattliche Versicherung und Verhaftung: eine Einführung in das Verfahren zur Abnahme der eidesstattlichen Versicherung durch den Gerichtsvollzieher, Jur. Verl. Pegnitz, Pegnitz, 2007, pp. 25-38.

62 Verde, Giovanni,"La riforma dei libri III e IV del codice di procedura civile. Appendice di aggiornamento al febbraio" en Profili del processo civile Ed. Jovene, Napoli, 2006, pp. 460 y ss.

63 Verberke, La transparence, cit. nota n. 52, pp. 27-45. 
Álvaro Pérez Ragone

Oscar Silva Álvarez

secreto profesional (como es el secreto bancario) pueden impedir que terceros suministren información ${ }^{64}$. La rigidez del secreto profesional y, específicamente, del mencionado secreto bancario, sólo puede ser flexibilizada si el deudor consiente. En relación con lo anterior, el art. 18 de la ley 19.628, sobre protección de la vida privada, establece la posibilidad que los terceros responsables de los registros o bancos de datos personales puedan informar sobre ello a los tribunales de justicia, con ocasión de requerimientos efectuados por estos en el marco de juicios pendientes. Sin embargo, para los efectos de una ejecución, dicha información podría resultar no tan relevante, toda vez que se refiere a datos sobre el pasivo de una persona y no sobre su activo.

Siempre en esta materia, el art. 154 de la Ley General de Bancos establece el secreto bancario de los depósitos y captaciones de cualquier naturaleza en que intervenga la institución financiera como receptor. Las excepciones, también relativas a requerimientos de orden judicial, suponen el conocimiento del juez o de quien solicita a éste el requerimiento, relativo a operaciones específicas de la parte (deudor en este caso), entendiéndose que no podría hacerse mención a estados financieros generales de una persona, que pudiesen ilustrar adecuadamente su activo. Huelga señalar que las entidades bancarias suelen ser muy estrictas con la reserva bancaria, cuestión que también entorpece, objetivamente al menos, el acceso a información muy relevante para la efectividad de la ejecución.

No obstante todo lo antes indicado, existen algunas situaciones, especialmente en el contexto de comenzar una relación de negocios o al solicitar un crédito, en las que los deudores tienen un interés de divulgar información acerca de su solvencia. Ejemplo de lo anterior es la autorización para la recolección de datos acerca del estado financiero de un futuro cuentacorrentista, de frecuente ocurrencia práctica. Si se considera una realidad como la anteriormente descrita, no se entiende entonces cuál sería el obstáculo insalvable para que esa misma información pudiese ser empleada, dentro de la ejecución, por el órgano competente y el acreedor ${ }^{65}$.

El uso de los sistemas informáticos y de la tecnología de la información al servicio de aquél que desea emprender una relación negocial, para conocer la bonitas en solvencia de su contraparte, no es objetada por aquél que desea endeudarse y, consecuentemente, transparenta su conducta y patrimonio como futuro deudor. Nada justifica que este manejo de la información no sea accesible para quien, siendo acreedor, no dispone normalmente del conocimiento relativo a la masa de información poseída por una entidad acreedora profesionalizada y con la tecnología suficiente para efectuar tal manejo de datos. Pero ésta última podría, sin embargo, brindar la

\footnotetext{
64 Stamm, Jürgen, Die Prinzipien und Grundstrukturen des Zwangsvollstreckungsrechts. Ed. Mohr Siebeck, Tübingen,2007, pp. 703-720.

65 En detalle, véase Comisión de las Comunidades Europeas (2008).
} 
El imperativo de transparencia patrimonial del deudor como requisito funcional para una ejecución civil eficiente The transparency of debtors` assets as a functional requirement for an efficient civil enforcement

información necesaria y adecuada al primero si ello se encausa en un proceso de ejecución actual o inminente ${ }^{66}$.

Otro problema, vinculado con el manejo de la información, es que ésta puede terminar siendo utilizada por la entidad que la conoce, en su propio beneficio. Un ejemplo asiduo en la vida comercial es clarificador en este sentido: normalmente, al celebrar algún contrato relativo a un producto bancario, como una cuenta corriente con una línea de crédito asociada a ésta, se establece que la institución financiera podrá, en caso de existir saldos pendientes por cualquier causa, proceder a descontar, sin mayores trámites, los dineros que sean depositados en la cuenta corriente respectiva ${ }^{67}$. Es el efecto propio del manejo de la información por parte de un acreedor profesional, ya que no debe perderse de vista que las instituciones financieras son las que ocupan la mayor parte del actual aparato ejecutivo civil, dejando relegados a los acreedores no profesionales a un segundo plano ${ }^{68}$.

Esta situación, que es asumida sin mayores cuestionamientos por el mercado, es manifestación de la utilidad que tiene acceder a la información patrimonial del deudor. Incluso, se trata de un caso en que el acreedor puede ir satisfaciendo su crédito, en ocasiones sin intervención alguna del órgano jurisdiccional, y pudiendo vulnerar disposiciones como las relativas a los bienes inembargables (piénsese, por ejemplo, en la hipótesis en que a una persona le depositan sus remuneraciones en una cuenta corriente, y dicho dinero es inmediatamente descontado por la entidad acreedora).

Sin embargo, lo anterior genera, al mismo tiempo, una injusta asimetría entre el acreedor profesional y el que no lo es, cuestión de la cual debe hacerse cargo el legislador, en la medida de lo posible.

\section{3- La intervención del deudor como proveedor de su información patrimonial.}

El deudor como fuente de información sobre sus activos es la principal herramienta para la conformación del ámbito patrimonial de agresión ejecutiva. Imponer al ejecutado este deber

Maier, Isaac, 2008 "Die dogmatische Situation des Vollstreckungsrechts aus Sicht des schweizerischen “, ZZP, No 121, , pp. 296 y ss.

67 Sobre las implicancias económicas de la posibilidad a los activos financieros en entidades bancarias tomando como fenómeno el "embargo online" existente en Brasil puede verse Barbosa, Fabiano Jantalia «A Penhora on line de ativos financeiros: reflexões sobre o aprimoramento do Código de Processo Civil brasileiro à luz da análise econômica do Direito», 2007. Berkeley Program in Law \& Economics. Latin American and Caribbean Law and Economics Association (ALACDE) Annual Papers. Paper 050207-20. http://repositories.cdlib.org/ bple/alacde/050207-20 (visitada el 10 de agosto 2009).

68 Similar situación ocurre, por ejemplo, en Italia, en donde la doctrina resalta la apropiación del sistema de ejecución por parte de la Banca. Vgr. Capponi, Bruno, "Astreintes nel processo civile italiano", en Studi sul processo di espropriazione forzata, Ed. Giappichelli, Torino ,1999, p. 150. 
Álvaro Pérez Ragone

Oscar Silva Álvarez

de información o que "descubra" su patrimonio (discloussure of assets) es una alternativa que ha tenido buen funcionamiento en la $\mathrm{UE}^{69}$.

En doctrina pueden distinguirse algunos modelos de declaración, adoptando diferentes criterios. El primero obliga al deudor a divulgar todos sus activos, mientras que el segundo restringe esta obligación a los activos suficientes para la recuperación de lo requerido por el acreedor. En este ámbito varían los sistemas en relación a la intensidad y extensión de este deber: o se reduce la información al monto del crédito a satisfacer como es el caso de Portugal o España; o bien debe declararse la totalidad de los activos, como es el caso de Austria, Alemania e Inglaterra. Si uno u otro sistema se manifiesta como el más coherente y adecuado es materia de discusión. Sólo hay que tomar como modelo la larga disputa dada en Italia al respecto, para defender una u otra postura, discusión directamente vinculada con la proporcionalidad y adecuación de las distintas medidas ejecutivas ${ }^{70}$.

Otro detalle importante es contar con incentivos y facilidades para el deudor, a los efectos que cumpla con su deber, y lo haga en forma cabal y confiable. Las distintas variables van desde mecanismos en formato preconstituido como declaración jurada, como es el caso de Alemania, hasta declaraciones ante los órganos de ejecución u otro ministro de fe, como es el caso flexible de los países escandinavos y el Reino Unido. Cumplir o no con una orden judicial al respecto acarrea, por regla general, consecuencias que son coercitivas y, por tanto, de incentivo. Por otro lado la información recabada puede ser registrada y tener, en los casos de registros de insolvencia por ejemplo, un alcance mayor al inicialmente predispuesto en relación a un proceso particular ${ }^{71}$.

Suele afirmarse que la primera alternativa no parecería adecuarse a principios básicos de la ejecución singular y de las medidas cautelares, encabezados por el de proporcionalidad. Ello puede resultar atendible en la medida que la declaración de bienes del deudor produzca, por sí sola, el embargo, tal como ocurre en el derecho italiano, a la luz del art. 492 del Codice di Procedura Civile. Sin embargo, no hay que perder de vista el hecho que, por la sola divulgación patrimonial a partir de la declaración del deudor, no se está afectando ningún bien en particular, salvo que el legislador considere dicha forma de embargo, lo que no ocurre en nuestro modelo procesal ejecutivo actual. En cuanto a la segunda alternativa, puede aun distinguirse entre dos especies de modelos abstractos, de acuerdo a quién pueda hacer la selección

69 Ver Sander, Eric, "La publicité fonciere, vers des registre en ligne?" en L'exécution inmobiliaire en Europe, Ed. Juridique et technique, Paris, 2005, pp. 19-30.

70 Cordopatri, Francesco, 2005, "Le nuove norme sull'esecuzione forzata", in Rivista di Diritto Processuale, pp. 760-782; Miccolis, Secondo, "Pignoramento, ricerca dei beni da pignorare, estensione del pignoramento", in AA.VV., Le modifiche al codice di procedura civile previste dalla l. $n$. 80 del 2005, in Foro it., 2005, V, pp. 114-116.

71 Mello, Roberto Munhoz, 2007 , "La nuova discipplina degli obblighi del terzo debitore ex art. 546 C.P.C", en Rivista di Diritto Processuale LXII, n. 1 pp. 133 y ss. 
El imperativo de transparencia patrimonial del deudor como requisito funcional para una ejecución civil eficiente The transparency of debtors` assets as a functional requirement for an efficient civil enforcement

de los bienes a embargar. En este contexto, desde la perspectiva del acreedor puede ser que un modelo en que la selección de bienes sea efectuada por el deudor sea desventajoso. Además, visto desde el deudor, éste podría limitar el acceso, pensando en varias oportunidades en que develaría secciones o partes de su activo $^{72}$.

Ante este dilema, algunos sistemas consagran un deber de información al inicio o antes de la ejecución, mientras otros presuponen y exigen un proceso iniciado. En muchos otros países el deudor puede ser obligado ya desde el inicio de la ejecución a declarar sus relaciones patrimoniales y, en todos los casos, mencionar quién es su empleador ${ }^{73}$. Por el contrario, en algunos países como Alemania, hasta antes de la reciente reforma del año 2009, por regla general el acreedor sólo podía exigir que el deudor efectuara la presentación de un informe detallado de su patrimonio ("declaración asegurada mediante juramento»), siempre y cuando ya se hubiesen iniciado las medidas de ejecución y éstas no hayan conducido a la satisfacción del acreedor ${ }^{74}$. Cabe señalar que éste era un sistema bastante criticado por la doctrina ${ }^{75}$. Idéntica solución (a la recientemente derogada regulación alemana) adopta el artículo 397 del Proyecto de Código Procesal Civil chileno.

Siempre en el caso alemán, la ley del 29 de julio de 2009 reforma las mencionadas normas sobre el esclarecimiento e información en la ejecución. Así, las nuevas disposiciones, con entrada en vigencia plena en el año 2013, persiguen fortalecer la posición y rol del oficial de de ejecución para obtener la información patrimonial necesaria. En efecto, luego de transcurrido el plazo legal de dos semanas, puede el oficial de ejecución exigir del deudor una completa información patrimonial cuya veracidad y corrección deben asegurarse por parte del deudor a través de una declaración jurada que se registra en un protocolo. El detalle patrimonial servirá para que el oficial de ejecución pueda elaborar un informe preciso, configurándose un documento electrónico, cuya custodia y registro queda en poder de un tribunal de ejecución centralizado para reserva de la información. Si el deudor no cumple cabalmente con el deber de información patrimonial (no informando o haciéndolo faltando a la verdad) y no pudiéndose arribar a la completa satisfacción del acreedor, queda autorizado el oficial de ejecución para poder obtener información incluso de terceros ${ }^{76}$. Así, podría acceder a la compañía aseguradora y de pensión

72 En detalle sobre el tema Miccolis, "Pignoramento", cit. nota n. 70, pp. 111 y ss.; Mello, "La nuova", cit. nota n. 71 pp. 133 y ss.

73 Así para Inglaterra Part 71 Civil Procedure Rules (CPR) y el Attachment of Earnings Act 1971 und County Court Rules order 27 schedule 2, ver en detalle para los Estados Unidos, Suiza, Baur/Stürner/Bruns cit. not. 44, Rn. 107, 119, Rn. 129 y Austria las disposiciones $\S 55,249$ a Exekutionsordnung (EO) y en detalle Baur/ Stürner/Bruns cit. not. 45, Rn. 146

$74 \quad$ Así el $§ 807$ ZPO y el relacionado con la declaración jurada §§ 836 Abs. 3, 2, 883, 2 ZPO.

75 Comp. Baur/Stürner/Bruns cit. nota 45, Rn. 4.7, 4.8.

76 Así la Ley de reforma de Información sobre la causa en la ejecución "Gesetz zur Reform der Sachaufklärung in der Zwangsvollstreckung” del 29/7/ 2009, (Diario Oficial) BGB1. I p. 2258; así las reformas a los §§ 802a, 2, Nr. 2, 802c y ss. ZPO. 
Álvaro Pérez Ragone

Oscar Silva Álvarez

impuesta por ley o la Oficina Federal de registro automotor, quienes pueden ser instados bajo apremio a informar ${ }^{77}$. Esta alternativa aportada por la reforma se acerca mucho más a los países en los cuales se exige en forma inmediata una completa información patrimonial, atribuyendo dicha función al oficial de ejecución como órgano competente.

\section{4- El rol cooperativo de los terceros}

Quienes pueden tener mayor objetividad, interés y certeza son, en muchos casos, los terceros que se relacionan como acreedores o deudores con el ejecutado, desde una institución financiera hasta el mismo empleador. En este ámbito, la necesidad de una regulación adecuada para el resguardo de la intimidad, privacidad y confidencialidad patrimonial relevante (el caso del secreto bancario o industrial) asume un rol protagónico.

La determinación de los requisitos a cumplir dentro de un proceso de ejecución, y correlativamente el deber impuesto a estos terceros dentro de márgenes de ponderación son esenciales para un adecuado funcionamiento del manejo de la información ${ }^{78}$.

\section{5- La posibilidad instar por la información a través medidas coercitivas.}

En relación con el deber de transparencia patrimonial, surge la natural interrogante acerca de la forma de incentivar dicha conducta procesal. En una primera lectura, podría descartarse, de plano, la posibilidad de compeler al deudor a cumplir con el mencionado deber a través de apremios corporales ${ }^{79}$, debido a las prohibiciones impuestas por los TTII de DDHH ratificados por Chile. Sin embargo, una mayor reflexión podría abrir, al menos, la posibilidad de imponer medidas coercitivas de este tipo bajo la forma de apremio por la falta de colaboración procesal, cuestión diversa a lo que comúnmente se conoce como prisión por deudas.

Por otra parte, generalmente se estima como posibilidad aceptable la de imponer medidas

$77 \S 8021 \mathrm{ZPO}$ en la nueva redacción.

78 Así la preocupación en la UE con el Libro Verde del año 2006 sobre embargo de activos bancarios, ver en detalle DIZ, Fernando Martín, "Protección procesal del crédito transfronterizo en la Unión Europea: propuesta de orden de embargo de activos bancarios", Revista de Derecho Comunitario Europeo, Año n ${ }^{\circ} 12, N^{\circ} 30,2008$, pp. 381-418; por cierto merece mención la existencia ya en Brasil del "Penhora online" o "embargo online", que permite a los jueces efectuar directamente la traba del embargo sobre depósitos bancarios medienate un sistema informático sobre la base de un Convenio del Poder Judicial con el Banco Central. El sistema ha demostrado hasta ahora una gran eficiencia con resguardo absoluto del secreto bancario, ver al respecto Neves, Daniel , "Penhora de dinheiro on line e de faturamento da empresa", Reforma do CPC 2, Ed. Revista dos Tribunais, Sao Paulo, 2007, pp. 282-299; ver igualmente el estudio crítico de Barbosa, Fabiano Jantalia , A Penhora on line de ativos financeiros: reflexões sobre o aprimoramento do Código de Processo Civil brasileiro à luz da análise econômica do Direito», en el mismo texto pp. 300 y ss.

79 Sin perjuicio que, como veremos, dicha figura se encuentra establecida en materia tributaria. 
El imperativo de transparencia patrimonial del deudor como requisito funcional para una ejecución civil eficiente The transparency of debtors` assets as a functional requirement for an efficient civil enforcement

coercitivas de índole pecuniaria, dentro de las cuales podemos ubicar las denominadas astreintes, que son multas caracterizadas por su periodicidad. A pesar que la contemplación de este sistema de ejecución indirecta tuvo su origen respecto de obligaciones de hacer o de no hacer, el PCPC opta por esta última medida en la ejecución dineraria, como coadyuvante del deber de transparencia o, si se quiere, como un instrumento destinado a garantizar, al menos tendencialmente, el equilibrio en la disciplina del cumplimiento de las obligaciones, procurando su cumplimiento oportuno, espontáneo e íntegro ${ }^{80}$. Esta previsión es aplicable tanto en relación tanto al deudor como a los terceros que se muestren renuentes a cumplir con los deberes de información, tal cual lo contempla el proyecto legislativo recientemente ingresado al Congreso Nacional.

Sin embargo, bien puede dudarse acerca de la eficacia práctica de la amenaza de pagar una suma de dinero que, sin embargo, no superará el monto de la obligación cuyo cumplimiento se persigue, y que el deudor conoce de antemano. Así las cosas, no parece en principio muy razonable confiar la efectividad del sistema de transparencia, y menos del cumplimiento mismo de las obligaciones, exclusivamente a un mecanismo como el planteado; sin perjuicio que, además, supone que la situación económica del sancionado permita que la multa opere como conminación efectiva.

\section{6- El tercero subrogante como sujeto de satisfacción del crédito y no simplemente como fuente de información.}

El activo del deudor/ejecutado está integrado por los créditos que tenga contra terceros. Este postulado precisa de una regulación adecuada para coadyuvar a la cobertura del crédito del ejecutante (garnishment en la terminología anglosajona). El activo compuesto por los beneficios bancarios, financieros, laborales, trusties, etc. no sólo pueden informar (por medio de sus tenedores), sino directamente satisfacer (con los resguardos adecuados) el crédito del ejecutante. Pero estos terceros tienen una característica adicional: se interrelacionan para el cumplimiento de sus actividades. Por ejemplo, el ejecutado tendrá una cuenta bancaria en una entidad, en la cual el empleador ingresará el pago de las remuneraciones.

El ejercicio de la histórica acción subrogatoria, se ve enormemente facilitado por la interconexión facilitada mediante las nuevas tecnologías. El tercero necesita ser notificado simplemente para que efectúe el pago a quién corresponda por ejemplo al órgano de ejecución. Asumirá entonces el tercero un rol de agente retenedor a favor del ejecutante, a través del órgano que esté actuando en la ejecución o en forma directa por el acreedor, según las distintas

80 Marazia, Lanfranco, 2004, "Astreintes e altre misure coercitive per l'effettività della tutela civile di condanna", Rivista della Esecuzione Forzata, n. 2, p. 338. 
Álvaro Pérez Ragone

Oscar Silva Álvarez

alternativas de regulación. Pero el tercero podría también oponerse a la orden de no pago (y de retención y/o pago al acreedor ejecutante u órgano ejecutivo), en cuyo cayo deberá justificar en contradictorio su negativa ${ }^{81}$.

Así, asumen un rol decisivo la coordinación y diseño de sistemas de comunicación efectivos entre el órgano de ejecución y estos terceros, que ya de por sí están integrados en sistemas con las nuevas tecnologías para el cumplimiento de sus propias actividades.

Finalmente, existiendo en un mayor o menor grado de perfección estas interrelaciones, las órdenes de retención (embargos) u otras medidas de ejecución cuyos destinatarios son terceros que tienen esta relación con el ejecutado, varían también en tanto existan pluralidad de acreedores y cómo son tratados: preferencias temporales, privilegios o trato igualitario e indiferente ${ }^{82}$.

\section{Situación en el derecho nacional.}

Es posible realizar una escisión teórica entre los conceptos de patrimonio ejecutable y de transparencia patrimonial. El primero de ellos corresponde a la esfera del derecho civil, que establece, en términos genéricos, el llamado derecho de garantía general del acreedor. Dicho concepto, consagrado legalmente en el art. 2465 del CC y complementado por la norma contenida en el art. 2469 del mismo cuerpo legal, no es sino la expresión más amplia del conjunto de medidas de protección del derecho de crédito, aunque al mismo tiempo constituye el marco que circunscribe la responsabilidad de los deudores a la esfera exclusivamente patrimonial, sin que pueda ser afectada su libertad personal en este ámbito.

El concepto de derecho de garantía general es el antecedente directo para el estudio de la ejecución y de la idea de la transparencia, propia del derecho procesal y que tiene un papel central en la efectividad del derecho de garantía general del acreedor.

Ver un estudio completo y comparado en Kofmel Ehrenzeller, Sabine, Der vorläufige Rechtsschutz im internationales Verhältnis, Mohr Siebeck, Tübingen, pp. 183-187; comp. Becker, Colin, First in time first in right, Duncker \& Humboldt, Berlin, 2000, pp. 82-86; comp. con las distintas meditas de resguardo de los actives del ejecutado según Ingman, Terence, The English Legal Process, Oxford Univ. Press, New York, pp. 431-436.

82 Comp. Becker, Colin, First in time first in right, Duncker \& Humboldt, Berlin, 2000, pp. 26-42; así en el sistema francés pese al conocido principio del patrimonio del deudor como prenda común, tiene un sistema diferencial de trato a los acreedores que agredan el patrimonio del ejecutado en un tiempo anterior a otros, creando una suerte de prelación. Téngase presente la famosa disposición: "Art. 2285 Code civil 2006 (con el símil Art. 2093 Code civil 1804): "Les biens du débiteur sont le gage commun de ses créanciers; et le prix s'en distribue entre eux par contribution, à moins qu'il n'y ait entre les créanciers des causes légitimes de préférence". 
El imperativo de transparencia patrimonial del deudor como requisito funcional para una ejecución civil eficiente The transparency of debtors` assets as a functional requirement for an efficient civil enforcement

Sin perjuicio de lo antes indicado, la gran preocupación de la doctrina de la época del Estado liberal era proteger la libertad del ciudadano contra la posibilidad de arbitrariedad estatal y, consecuentemente, con un uso indebido del poder jurisdiccional ${ }^{83}$. Dicha constatación, que se vincula en principio con una limitación y estricta tipificación de los medios de ejecución, puede también proyectarse y explicar, en gran medida, el hecho que en nuestro país el legislador haya dejado sujeta la satisfacción de los créditos, al menos en la primera parte del procedimiento ejecutivo, a la sola capacidad indagatoria del acreedor, siendo coherente con el pasivo papel que el juez tiene a lo largo del CPC y plasmando, por omisión regulatoria, el antiguo brocardo romano: jurisdictio in sola notio consistit ${ }^{84}$.

En efecto, si se observa la realidad legislativa nacional en materia de ejecución civil, se constata una palmaria desregulación de un sistema de medidas que coadyuven en la mayor transparencia posible del patrimonio del ejecutado. El aparataje coercitivo en que se manifiesta el imperio jurisdiccional no alcanza la primera de las etapas constitutivas del embargo, lo que, como ya hemos analizado, en la actualidad resulta ilógico y claramente insuficiente, de cara a la obtención de una tutela judicial efectiva.

El serio inconveniente que supone la inexistencia de una regulación adecuada acerca de la transparencia patrimonial se traduce en consecuencias ciertamente perniciosas para la efectividad de la tutela ejecutiva. Un ejemplo concreto de esta afirmación se encuentra en la indiscriminada utilización de los procedimientos de tercería en el juicio ejecutivo. Conocido es en el foro, que estas intervenciones de terceros en el procedimiento ejecutivo son, muchas veces, ejercidas al amparo de un panorama normativo permisivo y que deja en la más completa nebulosa todo lo relacionado con la transparencia patrimonial del ejecutado, con lo que las posibilidades de confundir los bienes del ejecutado con los de terceras personas aumentan considerablemente.

Como se viene señalando, el tema de la transparencia patrimonial del ejecutado adquiere una particular relevancia a propósito del embargo de bienes del deudor. Es en ese instante cuando se pone a prueba toda la estructura procedimental en materia ejecutiva. Sin embargo, en el CPC no existe estatuto normativo alguno, que se vincule con medidas, facultades, obligaciones o cargas encaminadas a la maximización de la transparencia patrimonial del ejecutado, en concordancia con la situación existente en el modelo español -del que nuestro CPC es tributario- hasta el año 1984, en que la antigua LEC fue objeto de una profunda reforma.

83 Marinoni, Luiz Guilherme y Cruz, Sergio, Curso de processo civil, Ed. Revista Dos Tribunais, San Pablo, 2007, vol. III, p. 50.

84 Sobre la función jurisdiccional ejecutiva comparar lo afirmado con lo enunciado por Navarrete Villegas, Luis G, Embargos, tercerías y realización de bienes, Editorial Jurídica de Chile, Santiago, 2004, p. 23. 
Álvaro Pérez Ragone

Oscar Silva Álvarez

Expresado en otros términos, la transparencia patrimonial del deudor, como fase inicial de la institución del embargo, ha sido totalmente ignorada por el legislador en el CPC, de tal suerte que, hoy en día, no hay regulación alguna que aborde esta etapa primitiva en la agresión patrimonial que debe sufrir el deudor que no cumple voluntariamente con la prestación a que se encuentra obligado.

\subsection{La solución en el CPC}

En realidad, el CPC centra su preocupación en aspectos distintos y, ciertamente, secundarios desde el punto de vista de la efectividad en la ejecución. Uno de estos aspectos consiste en determinar quién se encuentra legitimado para designar los bienes del deudor que serán embargados para satisfacer la acreencia que consta en un título ejecutivo. Así, entonces, puede hacer esta designación, en primer término, el acreedor, sea en su demanda ejecutiva (art. 443) o en el acto mismo del embargo (art. 447). De no suceder lo primero, es el deudor quien puede hacer la designación de sus bienes embargables, siempre que el ministro de fe encargado de practicar el embargo los estime como suficientes o, incluso sin serlo, no existan otros conocidos (art. 448). Finalmente, y sólo en defecto de las anteriores dos hipótesis, el ministro de fe puede realizar la designación de los bienes a embargar, y en tal caso se encuentra sujeto a un orden de prelación que, de manera estricta, establece el art. 449.

Como se puede apreciar, el legislador procesal civil ha prescindido de establecer algún mecanismo coadyuvante de la transparencia patrimonial del ejecutado. De hecho, una lectura de los preceptos antes citados muestra cómo, bajo la vigencia del actual sistema en materia procesal civil, la ley se limita a reconocer la posibilidad -que en los hechos casi siempre resulta ser una efectividad-, de que no existan bienes conocidos que puedan ser embargados para cubrir el crédito ejecutado. Por ende, en el CPC se asume la existencia de este problema, pero no se avanza hacia su solución definitiva o, al menos, un intento de mitigación.

Tan patente resulta este verdadero abandono legislativo en materia ejecutiva civil, que ni siquiera se plantea al acreedor la designación de bienes para el embargo en términos imperativos; evento que revelaría, al menos, la adopción de una postura definida respecto al tópico. De hecho, un análisis minucioso de las normas antes citadas permite afirmar, que no hay precepto alguno que señale que el acreedor debe encargarse de averiguar el paradero de los bienes embargables del ejecutado y singularizarlos en su demanda; sólo la omisión de esta designación es el presupuesto que utiliza el art.447 del CPC para permitirle al acreedor concurrir a la diligencia de embargo y, en ella, proceder a la designación, pero nada más.

$\mathrm{Si}$ a lo anterior sumamos la extensa regulación que contiene el art. 445 del CPC en relación a los bienes inembargables, la conclusión inevitable es que, para el legislador procesal civil chileno, el concepto de bienes embargables se determina por exclusión, sin delinear la manera en que dicha determinación se obtiene. 
El imperativo de transparencia patrimonial del deudor como requisito funcional para una ejecución civil eficiente The transparency of debtors` assets as a functional requirement for an efficient civil enforcement

\subsection{El panorama en otras leyes}

El panorama de la justicia civil antes descrito, contrasta con el existente en otras esferas del derecho nacional. Al respecto, en el área del derecho de alimentos, la ley 14.908, recientemente reformada por la ley 20.152 , establece un nuevo art. $5^{85}$, que constituye la principal y más decidida novedad en materia de transparencia patrimonial desde la perspectiva procesal, pero que, lamentablemente, se enmarca dentro de una serie de medidas protectoras del derecho de alimentos. En efecto, al proveer una demanda de pensión alimenticia, se le impone la obligación al juez de disponer que el demandado efectúe una serie de gestiones tendientes a acreditar su específica capacidad patrimonial, tales como el acompañamiento de determinada documentación o, en su defecto, la prestación de una detallada declaración jurada de patrimonio. Ambas conductas deben realizarse en la audiencia preparatoria, a la que el demandado es citado bajo apercibimiento de arresto.

“Art. 5. El juez, al proveer la demanda, ordenará que el demandado acompañe, en la audiencia preparatoria, las liquidaciones de sueldo, copia de la declaración de impuesto a la renta del año precedente y de las boletas de honorarios emitidas durante el año en curso y demás antecedentes que sirvan para determinar su patrimonio y capacidad económica. En el evento de que no disponga de tales documentos, acompañará, o extenderá en la propia audiencia, una declaración jurada, en la cual dejará constancia de su patrimonio y capacidad económica. La declaración de patrimonio deberá señalar el monto aproximado de sus ingresos ordinarios y extraordinarios, individualizando lo más completamente posible, si los tuviere, sus activos, tales como bienes inmuebles, vehículos, valores, derechos en comunidades o sociedades.

Para efectos de lo anterior, el tribunal citará al demandado a la audiencia preparatoria personalmente o representado, bajo apercibimiento del apremio establecido en el artículo 543 del Código de Procedimiento Civil.

Si el demandado no da cumplimiento a lo ordenado conforme al inciso primero, o si el tribunal lo estima necesario, deberá solicitar de oficio al Servicio de Impuestos Internos, a las Instituciones de Salud Previsional, a las Administradoras de Fondos de Pensiones y a cualquier otro organismo público o privado, los antecedentes que permitan acreditar la capacidad económica y el patrimonio del demandado.

El ocultamiento de cualquiera de las fuentes de ingreso del demandado, efectuado enjuicio en que se exija el cumplimiento de la obligación alimenticia, será sancionado con la pena de prisión en cualquiera de sus grados. El demandado que no acompañe todos o algunos de los documentos requeridos o no formule la declaración jurada, así como el que presente a sabiendas documentos falsos, y el tercero que le proporcione maliciosamente documentos falsos o inexactos o en que se omitan datos relevantes, con la finalidad de facilitarle el ocultamiento de sus ingresos, patrimonio o capacidad económica, serán sancionados con las penas del artículo 207 del Código Penal.

La inclusión de datos inexactos y la omisión de información relevante en la declaración jurada que el demandado extienda conforme a este artículo, será sancionada con las penas del artículo 212 del Código Penal.

Los actos celebrados por el alimentante con terceros de mala fe, con la finalidad de reducir su patrimonio en perjuicio del alimentario, así como los actos simulados o aparentes ejecutados con el propósito de perjudicar al alimentario, podrán revocarse conforme al artículo 2.468 del Código Civil. Para estos efectos, se entenderá que el tercero está de mala fe cuando conozca o deba conocer la intención fraudulenta del alimentante. Todo lo anterior es sin perjuicio de la responsabilidad penal que corresponda. La acción se tramitará como incidente, ante el juez de familia. La resolución que se pronuncie sobre esta materia será apelable en el solo efecto devolutivo". 
Álvaro Pérez Ragone

Oscar Silva Álvarez

Siempre en el mismo ámbito, el ya mencionado art. 5 le confiere al juez un inédito poder de investigación, que puede ejercer siempre que lo estime necesario, y que implica el acceso a sensible información patrimonial del demandado en un juicio de alimentos. En virtud de esta facultad, puede recabar información de, prácticamente, todo organismo público o privado, con el fin de construir el panorama económico del demandado de la forma más fehaciente posible.

A pesar que pueda entenderse dentro de un derecho históricamente más protegido, como es el de alimentos, una característica que llama bastante la atención es que el régimen antes descrito se aplica respecto a quien no es, aún, ejecutado. Podría estimarse como un argumento válido a la hora de insertar un estatuto similar, respecto de quien tiene, desde un comienzo, la calidad de acreedor respecto de una persona determinada.

Luego, en materia procesal tributaria encontramos dos preceptos relativos al tema. En primer término, el art. 168 del CT establece la facultad del Servicio de Tesorerías para, a través de los funcionarios nominativamente determinados por el Tesorero General, acceder al contenido de todas las declaraciones de impuestos que haya formulado el contribuyente, así como a toda la información que tenga el Servicio de Impuestos Internos sobre el deudor. Ello, con el fin de determinar los bienes del contribuyente, en el marco de la cobranza de las obligaciones tributarias.

En segundo lugar, el art. 171 del CT -que se encuentra dentro del título que regula el cobro ejecutivo de las obligaciones tributarias de dinero-, establece la facultad del recaudador fiscal para exigir del contribuyente ejecutado una declaración jurada de sus bienes, con el objeto de facilitar, entre otras diligencias, el embargo. Dicha exigencia puede, eventualmente, ir acompañada de apremios corporales -aplicables por la justicia ordinaria-, en caso que la negativa del ejecutado a prestar la declaración hiciere impracticable o insuficiente el embargo.

Estas dos instituciones, que corresponden a diversas categorías de medidas tendientes a la consecución de la transparencia patrimonial, constituyen una manifestación aislada, cuya explicación se encuentra en la ya antigua idea de la autotutela fiscal en materia tributaria, y que no corresponden a una voluntad general de favorecer la situación de todo acreedor, ante la realidad cotidiana de la difuminación patrimonial de los deudores. Sobre todo en el primero de los casos, estamos ante un claro ejemplo más de manejo de la información por un acreedor profesional, que se encuentra en una injusta ventaja respecto del resto de los acreedores, más allá de la prelación crediticia que pueda ostentar.

Luego, en materia procesal laboral, a propósito de la potestad cautelar incorporada por la ley 20.087, el nuevo art. 444 consagra -aunque en términos vagos- la facultad del juez de decretar todas las medidas que estime necesarias para asegurar el resultado de la acción, así como para la protección de un derecho o la identificación de los obligados y la singularización de su patrimonio. La última frase es, precisamente, una vía por la cual podría desarrollarse un marco regulatorio de la transparencia patrimonial, pero claramente con un carácter precario y, 
El imperativo de transparencia patrimonial del deudor como requisito funcional para una ejecución civil eficiente The transparency of debtors` assets as a functional requirement for an efficient civil enforcement

por lo demás, fuera del procedimiento ejecutivo propiamente tal, aunque esta circunstancia no debería significar un problema a la hora de aplicarlo dentro de dicha etapa procesal. En efecto, la ley se refiere a un obligado al pago (lo que supone la existencia de un crédito indubitado) y, por lo demás, si se permite al juez la realización de amplias diligencias para singularizar el patrimonio de un demandado, con mayor razón debería permitírsele respecto de un ejecutado. Siendo que esta norma y el ya mencionado nuevo art. 5 de la ley 14.908 son relativamente coetáneas, se genera una interrogante acerca de cuáles habrán sido los motivos tenidos en cuenta por el legislador, para no extender el marco protectivo del derecho de alimentos a otra área jurídica con una fuerte carga social, como es la del derecho del trabajo.

Fuera de todos los anteriores casos, la única norma que, también con un carácter impreciso, establece la posibilidad de proporcionar información con ocasión de un procedimiento judicial se encuentra en el ya visto art. $18^{86}$ de la ley $\mathrm{n}^{\circ} 19.628$, sobre protección de la vida privada, del año 1999. Sin embargo, y dejando a un lado las críticas indicadas anteriormente, la mención marginal que se hace a la posibilidad que tiene un tribunal para solicitar que sea proporcionada información patrimonial de una persona no está acompañada de la precisa forma en que dicha información podría ser solicitada, sus condiciones, alcances específicos y demás requisitos de procedencia.

\section{Algunos planteamientos relativos al proyecto de ley para un nuevo CPC.}

El mensaje con que se anuncia el PCPC señala que "un sistema democrático como el nuestro no se satisface con un reconocimiento de los derechos de las personas sino sólo cuando aquel reconocimiento lleva aparejado, siempre y bajo cualquier circunstancia, un sistema de tutela eficaz que proteja tales derechos ante las eventuales vulneraciones que puedan sufrir, y que permita junto con llegar a una solución justa, que ésta llegue en tiempo y se materialice con efectividad, a fin de satisfacer en forma real el quiebre de la paz social que implica tal vulneración. Sólo así se reconoce la verdadera existencia de los derechos" $" 87$. Posteriormente, ya en materia ejecutiva, el mismo mensaje agrega que "El valor de las soluciones, en la práctica, y el real reestablecimiento de la paz social ante la vulneración de derechos, se encuentra estrictamente determinado por su cumplimiento, bajo la constante posibilidad que ante su inexistencia el sistema completo se desacredite, y pierda todo sentido".

En todo caso, no destaca el mensaje ningún aspecto relacionado con la transparencia patrimonial del deudor.

"Art. 18. En ningún caso pueden comunicarse los datos a que se refiere el artículo anterior, que se relacionen con una persona identificada o identificable, luego de transcurridos cinco años desde que la respectiva obligación se hizo exigible.

Tampoco se podrá continuar comunicando los datos relativos a dicha obligación después de haber sido pagada o haberse extinguido por otro modo legal.

Con todo, se comunicará a los tribunales de Justicia la información que requieran con motivo de juicios pendientes". Mensaje del PCPC, disponible en http://www.minjusticia.cl/ (consulta: junio de 2009). 
Álvaro Pérez Ragone

Oscar Silva Álvarez

Yendo al texto del PCPC, un análisis preliminar nos permite concluir que se establece un régimen que combina la declaración de bienes efectuada por el propio deudor, con un poder moderado de investigación para el oficial de ejecución. Además, se establece un deber general de colaboración de las entidades y personas que sean depositarias de información patrimonial del ejecutado. Sin embargo, y siempre en la perspectiva de una opinión inicial, se trata de un tema no suficientemente desarrollado y cuya aplicación se vislumbra bastante complicada.

En primer término, los supuestos de operatividad de la manifestación de bienes implican que se establezca que el embargo no ha sido exitoso. A dicha conclusión puede arribarse, sea que conste claramente de los resultados del embargo o, bien, que el acreedor justifique esta circunstancia, cuestión que ya se vislumbra como de compleja aplicación. En último término, se contempla la manifestación de bienes ante la imposibilidad de ubicar al deudor en su domicilio, para poder ser notificado del despacho de ejecución (cuestión que abre la natural interrogante de cómo poder requerir la manifestación de bienes en este caso).

Cuestionable es también el establecimiento de medidas coercitivas de índole económica, para el deudor renuente a prestar declaración en la forma debida. Como dijimos anteriormente, compeler a un deudor con la generación de nuevas deudas (a partir de la imposición de multas) no parece razonable y necesariamente efectivo como incentivo de una conducta procesal que tienda, en último término, a obtener una prestación por parte de un deudor. Más poderosa es esta duda cuando se trata de una ejecución de prestaciones dinerarias, que es, justamente, el capítulo en que se comprende la existencia de esta medida. Por lo demás, la multa ni siquiera aparece como destinada a amortizar la deuda, sino que va a beneficio fiscal, lo que podría suponer, paradojalmente, disminuir el patrimonio ejecutable y, por lo mismo, las posibilidades de efectiva tutela del crédito; en pos de un marcado carácter publicista de la institución.

Por otra parte, si se comparan los incisos $2^{\circ}$ y $3^{\circ}$ del art. 397 del PCPC, se abre la posibilidad de imponer otro tipo de sanciones, diversas a las multas, pero que tampoco son descritas en el PCPC, y que sólo podrían ser reconducidas a las sanciones (también indeterminadas) que podría aplicar el juez en virtud del art. 6 del PCPC.

En relación a las facultades del oficial de ejecución en materia de investigación del patrimonio del ejecutado, sin perjuicio de deber proponerse su ejercicio por el ejecutante y tener que requerirse la información fundadamente, consideramos que se encuentran bastante limitadas y, en la forma propuesta, podría traducirse en una figura de escasa relevancia práctica, sobre todo teniendo presente que no se establece cuándo el ejecutante podría, por sí mismo, acceder a la información que se solicita.

Finalmente, la conducta no cooperativa por el silencio o falsa información que puede brindar el ejecutado tiene dentro del actual sistema una menor importancia, por ejemplo, que disponer de un bien embargado,,como si esto último fuera primero en el tiempo y lo más importante. Ambas conductas son graves y no es descabellado poder preveer un tipo penal que 
El imperativo de transparencia patrimonial del deudor como requisito funcional para una ejecución civil eficiente The transparency of debtors` assets as a functional requirement for an efficient civil enforcement

las contemplara, pero a ambas. De más está agregar que éste no es un caso aislado de pobre técnica legislativa, si se tiene en cuenta la deficiente justicia concursal y el casi ineficiente derecho penal económico-concursal.

\section{Comentarios finales.}

En general, el tema de la transparencia ha adquirido una inusitada importancia, no precisamente dentro del derecho procesal, sino que más bien vinculado a las actividades de los poderes del Estado. No obstante, a partir de ello es posible instar por la superación de las fronteras de lo público para predicar, en el ámbito de los particulares, modelos que protejan el indiscutido valor de la transparencia y que generen un estándar de conducta aplicable para toda persona. Una de esas manifestaciones se encuentra, precisamente, en materia de ejecución civil, donde, como hemos podido apreciar, una de las piedras angulares es la transparencia patrimonial del deudor.

Una información patrimonial en cumplimiento del deber de cooperación satisfecho por parte del deudor logran con certeza, ya al inicio del ejecución brindar una transparencia sobre las relaciones patrimoniales del deudor. De esta forma, es posible llevar adelante -con un prometedor éxito- medidas de ejecución en forma inmediata. Pero logra, además, otro resultado de economía procesal y de tiempo: los intentos de ejecución que desde un inicio permanecen como poco exitosos y de los cuales ni el acreedor, ni el órgano de ejecución pudieron tener conocimiento, podrán evitarse con visión de futuro.

El sistema que se termine imponiendo en lo que constituya el nuevo CPC, debe partir de una pretensión muy sencilla, y que considere la real posibilidad de que un deudor no tenga cómo satisfacer una pretensión. Sobre esa base, sin embargo, debe propugnarse un estatuto que, ponderando adecuadamente los intereses de las partes y, sobre todo, los del acreedor, incentive la transparencia y facilite al máximo el acceso a información patrimonial confiable, que cada vez se encuentra mejor organizada, y casi siempre en las manos de manejadores profesionales de datos.

De acuerdo a la propuesta planteada en el PCPC, es discutible el rol coadyuvante que pueda tener la imposición de multas para el ejecutado renuente, sobre todo cuando se trate de la ejecución de obligaciones dinerarias. Como se ha dicho, quien no quiere pagar una suma de dinero, no tendría por qué verse compelido a develar su patrimonio o parte de éste por una forma de coerción de igual naturaleza que la prestación que se niega a cumplir ${ }^{88}$. Y, finalmente, la estructura dedicada a la ejecución podría terminar ralentizándose aún más, al tener que ejecutar, además de la prestación, las multas derivadas por la falta de información y, por ende, de transparencia patrimonial. 